\title{
Kallikrein-Related Peptidase 14 Activates Zymogens of Membrane Type Matrix Metalloproteinases (MT-MMPs)_A CleavEx Based Analysis
}

\author{
Katherine Falkowski ${ }^{1,2}$, Ewa Bielecka ${ }^{1}{ }^{\circledR}$, Ida B. Thøgersen ${ }^{3}$, Oliwia Bocheńska ${ }^{2}$, \\ Karolina Płaza ${ }^{2}$, Magdalena Kalińska ${ }^{2}$, Laura Sąsiadek 1,2, Małgorzata Magoch 1,2 (D, \\ Aleksandra Pęcak ${ }^{1,2}$, Magdalena Wiśniewska ${ }^{1}$ (D), Natalia Gruba ${ }^{4}$, Magdalena Wysocka ${ }^{4}$, \\ Anna Wojtysiak ${ }^{4}$, Magdalena Brzezińska-Bodal ${ }^{4}$, Kamila Sychowska ${ }^{4}$, Anastasija Pejkovska ${ }^{5}$ (D), \\ Maren Rehders ${ }^{5}{ }^{\mathbb{D}}$, Georgina Butler ${ }^{6}$, Christopher M Overall ${ }^{6,7} \mathbb{D}$, Klaudia Brix ${ }^{5} \mathbb{D}$, \\ Grzegorz Dubin ${ }^{1}$, Adam Lesner ${ }^{4}$ (D), Andrzej Kozik ${ }^{2}$, Jan J. Enghild ${ }^{3}$, Jan Potempa ${ }^{2,8}$ \\ and Tomasz Kantyka $1,9, *$ (D) \\ 1 Malopolska Centre of Biotechnology, Jagiellonian University, 30-387 Krakow, Poland; \\ falkowski.katherine@gmail.com (K.F.); ewa.bielecka@uj.edu.pl (E.B.); lmsasiadek@gmail.com (L.S.); \\ m.magoch@gmail.com (M.M.); aleksandra.pecak@gmail.com (A.P.); wisienka.magdalena@gmail.com (M.W.); \\ grzegorz.dubin@uj.edu.pl (G.D.) \\ 2 Faculty of Biochemistry, Biophysics and Biotechnology, Jagiellonian University, 30-387 Krakow, Poland; \\ oliwia.bochenska@gmail.com (O.B.); plaza.karolina@gmail.com (K.P.); magda.kalinska@uj.edu.pl (M.K.); \\ andrzej.kozik@uj.edu.pl (A.K.); jan.potempa@uj.edu.pl (J.P.) \\ 3 Department of Molecular Biology and Genetics, Aarhus University, 8000 Aarhus, Denmark; \\ ibt@mbg.au.dk (I.B.T.); jje@mbg.au.dk (J.J.E.) \\ 4 Faculty of Chemistry, University of Gdansk, 80-308 Gdansk, Poland; natalia.gruba@ug.edu.pl (N.G.); \\ magdalena.wysocka@ug.edu.pl (M.W.); anna.wojtysiak@phdstud.ug.edu.pl (A.W.); \\ magdalena.brzezinska@phdstud.ug.edu.pl (M.B.-B.); kamila.sychowska@gmail.com (K.S.); \\ adam.lesner@ug.edu.pl (A.L.) \\ 5 Department of Life Sciences and Chemistry, Jacobs University Bremen, 28759 Bremen, Germany; \\ anja.pejkovska@gmail.com (A.P.); m.rehders@jacobs-university.de (M.R.); k.brix@jacobs-university.de (K.B.) \\ 6 Centre for Blood Research, Department of Oral Biological and Medical Sciences, \\ University of British Columbia, Vancouver, BC V6T 1Z3, Canada; george.butler@ubc.ca (G.B.); \\ chris.overall@ubc.ca (C.M.O.) \\ 7 Department of Biochemistry and Molecular Biology, University of British Columbia, \\ Vancouver, BC V6T 1Z3, Canada \\ 8 School of Dentistry, University of Louisville, Louisville, KY 40202, USA \\ 9 Broegelmann Research Laboratory, Department of Clinical Science, University of Bergen, \\ 5020 Bergen, Norway \\ * Correspondence: tomasz.kantyka@uj.edu.pl; Tel.: +48-12-664-61-07
}

Received: 14 May 2020; Accepted: 17 June 2020; Published: 19 June 2020

\begin{abstract}
Kallikrein-related peptidases (KLKs) and matrix metalloproteinases (MMPs) are secretory proteinases known to proteolytically process components of the extracellular matrix, modulating the pericellular environment in physiology and in pathologies. The interconnection between these families remains elusive. To assess the cross-activation of these families, we developed a peptide, fusion protein-based exposition system (Cleavage of exposed amino acid sequences, CleavEx) aiming at investigating the potential of KLK14 to recognize and hydrolyze proMMP sequences. Initial assessment identified ten MMP activation domain sequences which were validated by Edman degradation. The analysis revealed that membrane-type MMPs (MT-MMPs) are targeted by KLK14 for activation. Correspondingly, proMMP14-17 were investigated in vitro and found to be effectively processed by KLK14. Again, the expected neo-N-termini of the activated MT-MMPs was confirmed by Edman degradation. The effectiveness of proMMP activation was analyzed by gelatin zymography,
\end{abstract}


confirming the release of fully active, mature MT-MMPs upon KLK14 treatment. Lastly, MMP14 was shown to be processed on the cell surface by KLK14 using murine fibroblasts overexpressing human MMP14. Herein, we propose KLK14-mediated selective activation of cell-membrane located MT-MMPs as an additional layer of their regulation. As both, KLKs and MT-MMPs, are implicated in cancer, their cross-activation may constitute an important factor in tumor progression and metastasis.

Keywords: kallikrein 14; membrane-type MMP; CleavEx; fusion protein; zymogen activation

\section{Introduction}

The extracellular matrix (ECM) consists of a complex array of locally secreted macromolecules interacting as a meshwork of proteins, glycoproteins, glycosaminoglycans, and proteoglycans [1]. Proteases present within the ECM are essential for turnover of structural proteins or core protein components. In addition, proteolytic enzymes are required for the activation of growth factors and other ligands of cell surface receptors. Thereby, proteolytic processing of ECM components and the molecules stored therein provides both the structural organization and essential initial steps in cell-cell communication. By initiation of the signal transduction, proteases effectively regulate gene transcription eventually impacting on cell differentiation, proliferation, growth, and apoptotic programs [2]. Proteolytic enzymes essential for ECM homeostasis predominantly belong to the families of a disintegrin and metalloproteinase (ADAMs) [3], matrix metalloproteinases (MMPs) [1], and tissue kallikrein-related peptidases (KLKs) [4]. The MMP family is considered especially important for ECM remodeling [5,6]. In particular, the MMP proteases of the membrane-type subfamily (MT-MMPs) are essential in regulating cell migration during physiological wound healing [7] but are also implicated in cancer progression as they often involve in the initial steps of cancer cell metastasis [8-10]. Specifically, MMP14 (MT1-MMP) associates with integrins in endothelial cells at distinct cellular domains, which may initiate cell junction processing during invasion [11]. Furthermore, MMP14 is attributed as one of the main MT-MMPs implemented in activating cancer associated proMMP2 [12].

It is corroborated that the activation of MT-MMPs happens intracellularly by means of furin-mediated processing such that the active forms of MT-MMPs decorate the cell surface right upon secretory release of cellular products by exocytosis. This pathway is not exclusive, as extracellular processing of proMT1-MMP (proMMP14) has been reported [13,14]. About one-third of all proMMPs activation domains contain an Arg/Lys-rich motif, compatible with furin specificity, but also targeted by serine proteases, particularly plasmin $[15,16]$ and transmembrane serine proteinases hepsin and TMPRSS2 [17].

The family of human kallikrein-related peptidases consists of a total of 15 different serine proteases with trypsin-like, chymotrypsin-like, or mixed substrate specificity. Physiological roles of KLKs include regulation of cell growth and tissue remodeling [18]. Typically, KLKs and MMPs are co-expressed in many cell types and tissues [19-22]; therefore, understanding their interactions may provide a novel perspective for deciphering regulation of MMP activities in health and disease. A recent report has identified a pericellular network of KLK4, KLK14, MMP3, and MMP9 that are involved in initiation and promotion of prostate cancer cell metastasis [17]; however, the function of KLK14 in this complex was not identified.

Herein, we employed a new unbiased technique CleavEx (Cleavage of exposed amino acid sequences), which allowed us to test for the activation of MMP zymogen forms by KLK14. Our approach was based on the recombinant attachment of an MMP activation site sequence to the proteolytically stable heme-binding (HmuY) protein. Hybrid proteins displaying all 23 activation sequences of human proMMPs was expressed and purified. These proteins were then incubated with KLK14 and the generated products were subsequently analyzed to identify the potential processing. CleavEx analysis was followed by investigation of KLK14-mediated processing of native proMMP14-17. Lastly, 
we identified the cell surface processing of proMMP14 by KLK14. To our knowledge, this is the first study examining the potential of KLK family member to activate the proMMP family.

\section{Results}

\subsection{CleavEx $x_{\text {proMMP }}$ Fusion Protein Screening}

Hybrid proteins representative of each individual MMP propeptide sequence were created such that they are covalently engineered onto the proteolytic-resistant bacterial protein HmuY [23]. The hybrid proteins additionally featured an attached N-terminal extension constituting a HisTag followed by the respective proMMP activation sequence. This resulted in generating a total of 23 individual proteins, each exposing a sequence corresponding to the activation domain of the respective human prometalloproteinase. To verify the effectiveness of KLK14 in recognizing these peptide sequences, $25 \mathrm{ng}$ of each hybrid protein was incubated with increasing concentrations of KLK14

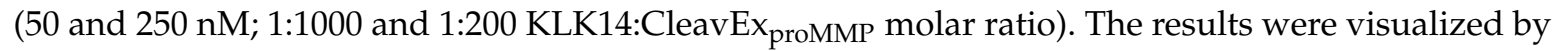
a HisTag-specific Western blot, where the loss of signal was indicative of the release of the HisTag via proteolytic removal of the fragment (Figure 1A). The stability of the full-length HmuY protein was verified independently, and no KLK14-mediated degradation was observed (data not shown). Among all 23 hybrid proteins tested in this manner, the sequences corresponding to proMMP11, proMMP14-17, proMMP21, proMMP24-25, and proMMP28 were recognized with highest effectiveness. This means that KLK14 at a concentration of $50 \mathrm{nM}$ was able to completely remove the HisTag from the respective hybrid proteins with HmuY. Note that CleavEx $x_{\text {proMMP23 }}$ was not cleaved at $50 \mathrm{nM} \mathrm{KLK14}$ but completely removed when $250 \mathrm{nM}$ KLK14 was used.

To visualize the efficiency of cleavage within the sequence motives of different CleavEx $x_{\text {proMMPs }}$ by KLK14, the Western blot results were scored and presented as a grey scale map (Figure 1B). In addition, all hydrolyzed CleavEx $x_{\text {proMMPs }}$ at $50 \mathrm{nM} \mathrm{KLK14}$ were further analyzed at 5, 25, and $50 \mathrm{nM}$ KLK14 (Figure S1). The data indicated a striking selectivity of KLK14 towards particular proMMP sequences. To determine which peptide bonds were hydrolyzed within the activation domains, and to exclude the possibility of HmuY cleavage by KLK14, N-terminal sequencing of each hydrolyzed product of the CleavEx $\mathrm{x}_{\text {proMMP }}$ reactions was performed. The determined N-termini nearly uniformly confirmed the expected P1 recognition site for KLK14 (Table 1). All of the CleavEx hybrid proteins, except for CleavEx $x_{\text {proMMP21, }}$, were hydrolyzed at the activation-specific location expected for KLK14.

\subsection{Processing of Recombinant proMMPs by KLK14}

Scanning of the hybrid proteins allowed for the selection of proMMPs that are likely activated by KLK14 in situ. To verify this contention, commercially available proMMP14, proMMP15, proMMP16 and proMMP17 were analyzed for KLK14-mediated activation in vitro. Firstly, we investigated the concentration requirements of KLK14-dependent hydrolysis of each proMMP. To this end, each proform was incubated with increasing concentrations of KLK14 for $1 \mathrm{~h}$ (approximately from 1:65 to 1:5 KLK14:MMP molar ratio) and was then subjected to SDS-PAGE analysis. During incubation, the pan-specific MMP inhibitor batimastat was present in the reaction mixtures to prevent autoactivation of the proMMPs. ProMMP2 which was unaffected by KLK14 in the CleavEx system served as the negative control (Figure 2A). In parallel, furin was also analyzed with both, proMMP2 and proMMP14 as a negative and positive control, respectively (Figure 2B,D). All four proMMPs tested were effectively cleaved in the presence of KLK14, even at the highest substrate:enzyme molar ratios with discrete bands at molecular masses corresponding to the loss of the $\sim 10 \mathrm{kDa}$ propeptides. Moreover, the extent of proteolysis progressed in a concentration-dependent manner with $50 \mathrm{nM}$ KLK14 (approximately 1:32 KLK14:MMP14 molar ratio) being sufficient to completely process proMMP14 (Figure 2C). Interestingly, in contrast to furin-mediated activation of MMP14, KLK14 incubation did not result in the accumulation of the $\sim 12 \mathrm{kDa}$ prodomain (Figure 2C,D). Higher concentrations of KLK14 were required for the full processing of other analyzed proMMPs. Nonetheless, $100 \mathrm{nM} \mathrm{KLK14}$ was sufficient 
to process proMMP15-17 (approximately 1:16 KLK14:MMP15-17 molar ratio) and the hydrolyzed products remained stable up to $250 \mathrm{nM}$ KLK14 (Figure 2E-G). Collectively, these results indicate that KLK14-mediated proMMP processing released stable, processed forms of MMP14-17.
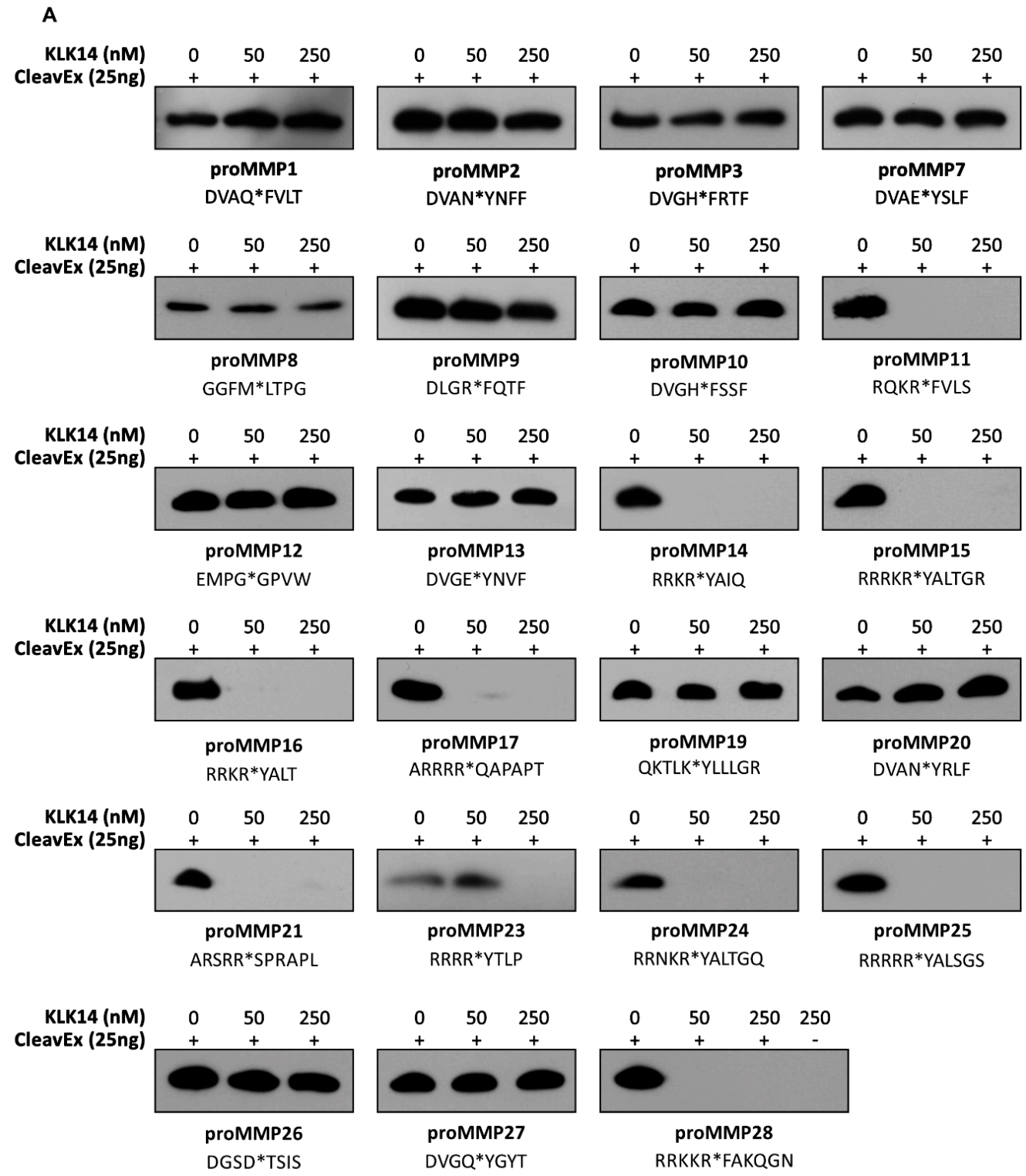

B
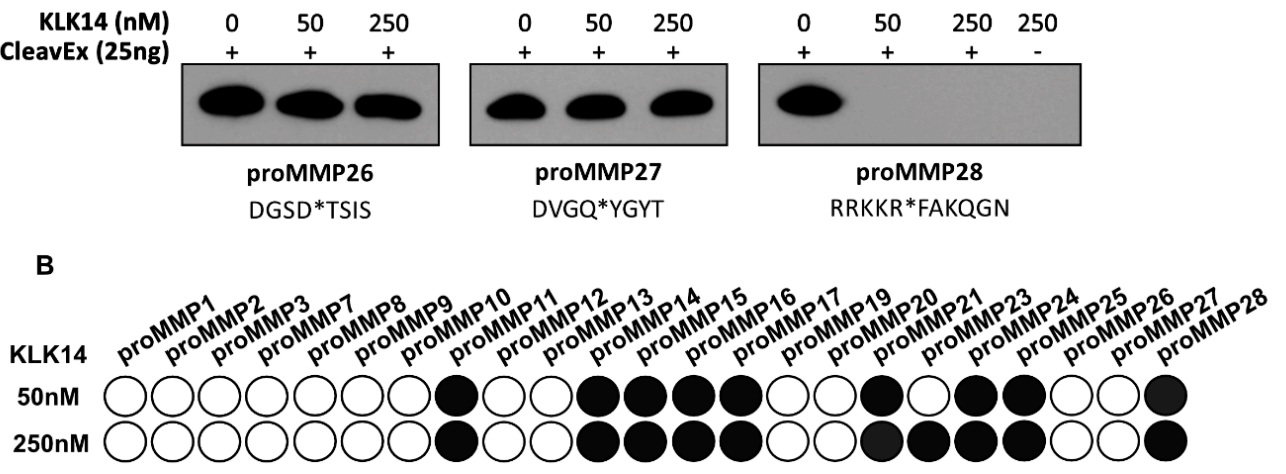

Figure 1. Effect of KLK14 on the CleavEx $x_{\text {proMMP }}$ fusion proteins. (A) Western blot analysis of each

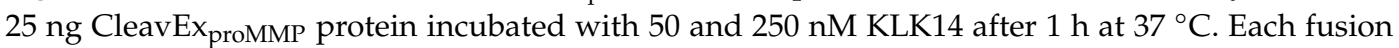
protein with its respective activation sequence is listed with the native site of hydrolysis indicated by an asterisk. (B) Schematic representation of the CleavEx $x_{\text {promMP }}$ fusion proteins from the Western blots in panel A. Scoring was performed by densitometry analysis using ImageJ. The shading is based on the quartile of change: $100-75 \%$ of control sample intensity is presented as white (no degradation); $75-50 \%$ as light grey; $50-25 \%$ as dark grey; and $25 \%$ and lower as black. KLK = kallikrein-related peptidase; CleavEx $=$ Cleavage of exposed amino acid sequences; $\mathrm{MMP}=$ matrix metalloproteinase 
Table 1. Identification of the KLK14 hydrolysis sites within the CleavEx $x_{\text {proMMP }}$ protein. CleavEx $x_{\text {proMMP }}$ fusion proteins were separated using SDS-PAGE and electrotransferred for N-terminal sequencing. Identified sequences are represented in the bold font and the underscore denotes where the location of the expected activation cleavage $\mathrm{P} 1-\mathrm{P} 1^{\prime}$ in the proMMP-derived sequence.

\begin{tabular}{|c|c|}
\hline CleavEx & Identified Sequence \\
\hline proMMP11 & RQKR ${ }^{27}$ FVLSDEP \\
\hline proMMP14 & RRKR $\underline{-}^{27}$ YAIQDE \\
\hline proMMP15 & RRRK $\bar{R}^{28}$ YALTGRD \\
\hline proMMP16 & RRK $\bar{R}^{27}$ YALTDEP \\
\hline proMMP17 & ARRR $\bar{R}^{28}$ QAPAPTDE \\
\hline proMMP21 & ARSRRSPR ${ }^{31}$ APLDEPN \\
\hline proMMP23 & RRRR ${ }^{27}$ YTLPDEPN \\
\hline proMMP24 & RRNKR ${ }^{28}$ YALTGQDE \\
\hline proMMP25 & RRRR $\bar{R}^{28}$ YALSGSDE \\
\hline proMMP28 & RRKK $\underline{R}^{28}$ FAKQGNDE \\
\hline
\end{tabular}

In addition to the products with the expected $10 \mathrm{kDa}$ shift, several other transient forms were observed and subjected to Edman sequencing for unambiguous identification. The $\mathrm{N}$-terminal analysis allowed for the assignment of the cleavage sites within the proform sequence (Table 2). First, the N-termini of all of the intact proforms, denoted as band 1 , were confirmed as corresponding with the reported sequences of proMMPs, providing an internal quality control. The single product, band 2MMP14, generated by KLK14-mediated proMMP14 processing, corresponded to the expected RRKR ${ }^{111} \downarrow$ YAIQ sequence, previously identified as the activation site [13]. Similarly, KLK14-mediated proMMP15 hydrolysis resulted in the accumulation of band $2_{\mathrm{MMP} 15}, P G K \mathrm{R}^{131} \downarrow$ YALT, consistent with the expected N-terminal sequence of the mature MMP15 [24]. Of note, despite the amino acids 128 and 129 being modified by the manufacturer from native arginine and arginine to proline and glycine, as indicated by italics above, KLK14 was able to generate the expected MMP15 active form. Furthermore, an additional product denoted as band $3_{\text {MMP15 }}$ was detected to be DLRG ${ }^{298} \downarrow$ IQQL. Surprisingly, this product did not correspond to the expected KLK14 preference and rather was consistent with MMP15 specificity [25]. ProMMP16 processing lead to the formation of the KLK14-produced mature form, as band $4_{\text {MMP16 }}$ corresponded to the anticipated RRKR ${ }^{119} \downarrow$ YALT hydrolysis. N-terminally truncated proforms were detected as band $2_{\mathrm{MMP} 16}$ and $3_{\mathrm{MMP} 16}$; however, only the $\mathrm{N}$-terminal of band $3_{\mathrm{MMP} 16}$ (KKPR $\left.{ }^{100} \downarrow C G\right)$ corresponded to the expected KLK14 specificity, while band 2 MMP16 (ALAA ${ }^{75} \downarrow M Q$ ) was consistent with MMP16 specificity [25]. ProMMP17 processing resulted in the generation of 4 bands. The first two bands, $1_{\mathrm{MMP} 17}$ and $2_{\mathrm{MMP} 17}$, observed in the untreated sample, were detected with identical $\mathrm{N}$-termini $\mathrm{A}^{39} \mathrm{PAPA}$, indicating the presence of differences in the C-terminal region of these proforms. KLK14 was able to process both proforms which resulted in the same sequential

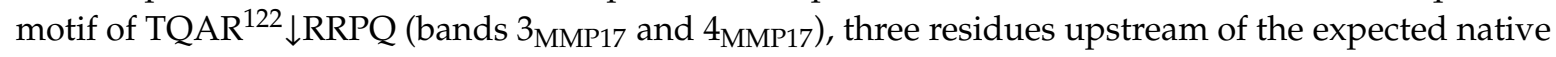
activation site.

To follow up on the concentration analysis, a time-course experiment was employed to detect product accumulation by SDS-PAGE. Specific time points were analyzed for $3 \mathrm{~h}$ with either $50 \mathrm{nM}$ KLK14 (proMMP14) or 100 nM KLK14 (proMMP15, proMMP16, and proMMP17) to observe the processing of each respective proMMP (Figure 3). Within $5 \mathrm{~min}$, the stable product, with the molecular weight corresponding to the active MMP14 form, began to appear and near complete processing was observed after $3 \mathrm{~h}$, resulting in the accumulation of the mature MMP14 form (Figure 3A). In contrast, MMP15 degradation progressed more slowly with the band corresponding to the processed active form appearing vaguely after $30 \mathrm{~min}$. Again, the product accumulated as a stable band, yet proMMP15 was not fully processed, even after 3 (Figure 3B). On the other hand, proMMP16 products accumulated already within $5 \mathrm{~min}$. All four bands identified by N-terminal sequencing appeared early, illustrating the efficient processing by KLK14. The fully matured active form appeared as the main band after $1 \mathrm{~h}$ of reaction and remained stable for the whole $3 \mathrm{~h}$ of incubation (Figure 3C). Again, similarly to 
proMMP15, proMMP17 maturation was not as efficient, as lower-molecular weight bands started to appear after $2 \mathrm{~h}$ of reaction, and complete processing of the proform could not be observed during the incubation (Figure 3D).
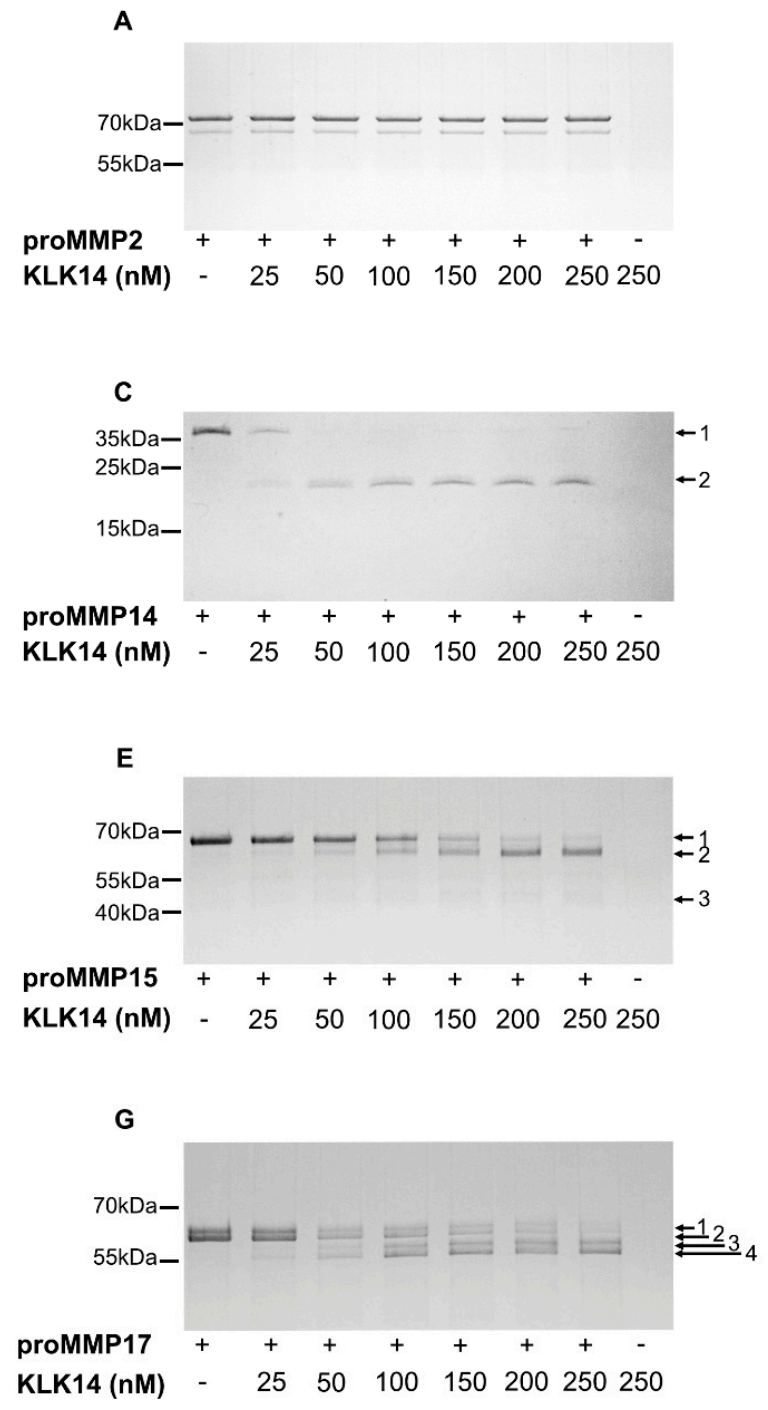
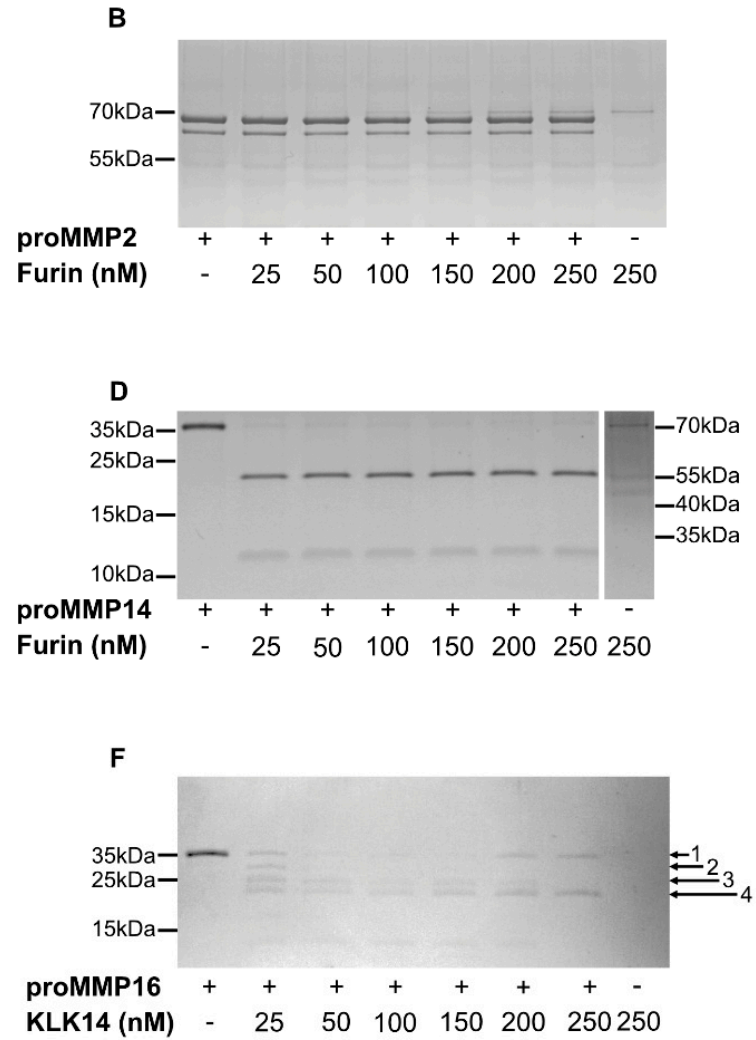

Figure 2. Concentration-dependent processing of proMMPs by KLK14. Each respective proMMP was incubated with increasing concentrations of $\operatorname{KLK} 14(\mathbf{A}, \mathbf{C}, \mathbf{E}-\mathbf{G})$ or furin $(\mathbf{B}, \mathbf{D})$ for $1 \mathrm{~h}$ at $37^{\circ} \mathrm{C}$ in the presence of $5 \mu \mathrm{M}$ batimastat, and the reaction products were analyzed by SDS-PAGE and visualized with Coomassie staining. Bands denoted with arrows were identified by N-terminal sequencing using Edman degradation (Table 2). KLK = kallikrein-related peptidase; $\mathrm{MMP}$ = matrix metalloproteinase. 
Table 2. N-terminal identification of KLK14-mediated processing of recombinant proMMPs. The KLK14 hydrolysis product sequences were analyzed by N-terminal sequencing using Edman degradation. The bold font denotes the amino acid sequences identified. The underscored residues represent changes to the native protein sequence, as reported by the manufacturer (R\&D Systems, Abingdon, United Kingdom). KLK14 recognized the sequence 3-aa upstream of the native MMP17 activation site, likely because the native site was modified by the manufacturer. All residues are numbered according to the Uniprot reported sequence of the full-length proteins. Bands are labeled according to the notation explained at Figure 2.

\begin{tabular}{|c|c|c|c|}
\hline Protease & Band & N-Terminal Sequence & Annotation \\
\hline \multirow{3}{*}{ proMMP14 } & 1 & $\mathrm{NH}_{2}-\mathrm{ALAS}^{24}$ LGSAQSSSFS & Proform \\
\hline & 2 & RRKR ${ }^{111}$ YAIQGLKWQH & Active form \\
\hline & 1 & $\mathrm{NH}_{2}-\mathrm{E}^{47}$ DAEVHAENWLLY & Proform \\
\hline \multirow[t]{3}{*}{ proMMP15 } & 2 & PGKR ${ }^{131}$ YALTGRKWNH & Active form \\
\hline & 3 & $\overline{\text { DLRG }^{298} \text { IQQLYGTPDGQP }}$ & Hinge region \\
\hline & 1 & $\mathrm{NH}_{2}-\mathrm{A}^{32}$ TVCGTEQYF & Proform \\
\hline \multirow{3}{*}{ proMMP16 } & 2 & ALAA $^{75}$ MQQFYGINMT & Truncated proform \\
\hline & 3 & KKPR $^{100}$ CGVPDQTRGS & Truncated proform \\
\hline & 4 & RRKR ${ }^{119}$ YALTGQ̄KWQ & Active form \\
\hline \multirow{4}{*}{ proMMP17 } & 1 & $\mathrm{NH}_{2}-\mathrm{A}^{39}$ PAPAPRAEDLSL & Proform \\
\hline & 2 & $\mathrm{NH}_{2}-\mathrm{A}^{39}$ PAPAPRAEDLSL & Proform \\
\hline & 3 & TQAR $^{122}$ RRPQAPAPTKW & Active form \\
\hline & 4 & TQAR $^{122} \mathbf{R R} \overline{\mathbf{P}} \mathbf{Q A P A P T K W}$ & Active form \\
\hline
\end{tabular}

A

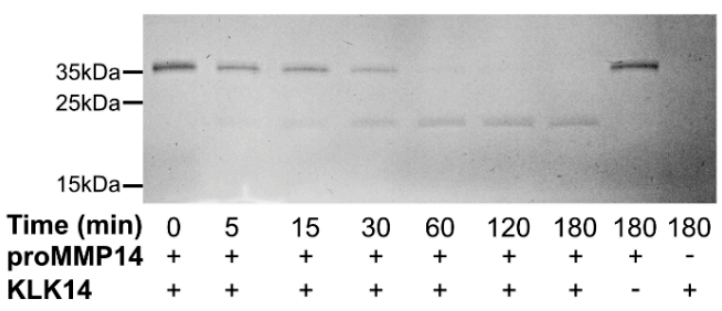

C

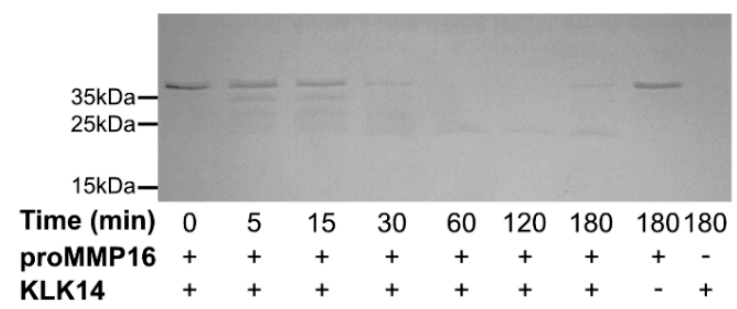

B

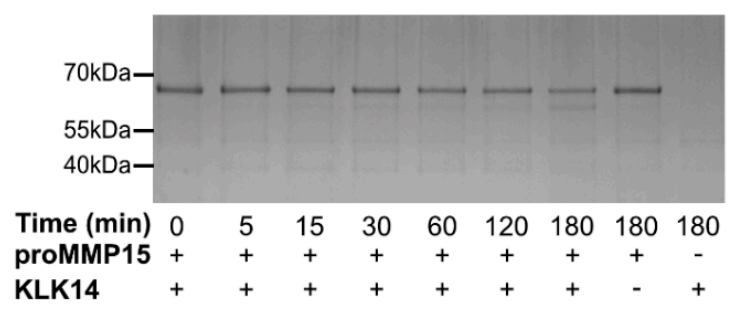

D

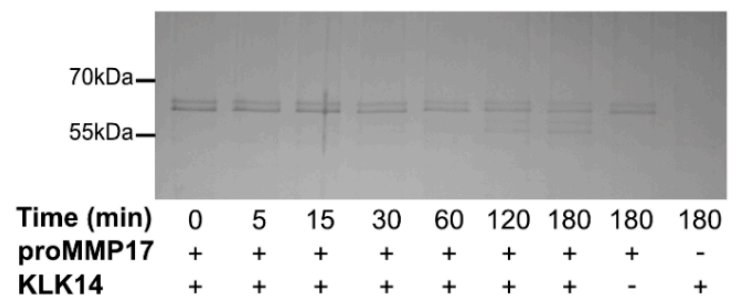

Figure 3. Recombinant human proMMP14,15, 16, and 17 are processed by KLK14 in a time dependent manner. (A-D) Respective proMMPs were incubated with KLK14 for 5, 15, 30, 60, 120, and 180 min, at $37{ }^{\circ} \mathrm{C}$ in the presence of $5 \mu \mathrm{M}$ batimastat. The reaction products at indicated timepoints were analyzed by SDS-PAGE and visualized via Coomassie staining. KLK = kallikrein-related peptidase; $\mathrm{MMP}=$ matrix metalloproteinase.

\subsection{Functional Activation of proMMPs by KLK14}

Each analyzed proMMP was activated with 50,100, or $250 \mathrm{nM}$ KLK14 for $1 \mathrm{~h}$ at $37^{\circ} \mathrm{C}$ followed by a gelatin zymography. No KLK14 activity was detected under experimental conditions, as evident by the lack of clear bands in the KLK14 control lanes (Figure 4A-E). As previously mentioned, proMMP2 was used as a negative control. Regardless of proMMP2 alone displaying residual activity on the zymogram gel, KLK14 treatment resulted in no observable processing after 250 nM KLK14 incubation 
(Figure 4A). In contrast, gelatinolytic activity and the expected molecular mass shifts were observed for proMMP14-16. At both 50 and $100 \mathrm{nM} \mathrm{KLK14,} \mathrm{proMMP14} \mathrm{was} \mathrm{processed} \mathrm{to} \mathrm{its} \mathrm{active} \mathrm{form} \mathrm{with}$ no difference in band intensity at either concentration (Figure 4B), indicating KLK14 concentrations equal or below $50 \mathrm{nM}$ as sufficiently efficient convertase. Interestingly, a portion of active MMP15 was observed with no treatment of KLK14, which suggested self-activation during the 1-h incubation (Figure 4C). Furthermore, KLK14 treatment of proMMP15 resulted in enhanced activation and active band accumulation at the expected molecular weight of around $55 \mathrm{kDa}$ at $100 \mathrm{nM} \mathrm{KLK14}$, in which intensity slightly decreased at $250 \mathrm{nM} \mathrm{KLK} 14$. In addition, lower molecular mass bands ( $\sim 35 \mathrm{kDa}$ ) were observed at both KLK14 concentrations, also displaying gelatinolytic activity. Part of these fragments likely corresponded to the DLRG ${ }^{298} \downarrow$ IQQL truncation identified from $\mathrm{N}$-terminal sequencing, as well as MMP15 self-degraded products, since no MMP inhibitor is present in the activity assay. As expected, proMMP16 was activated, and its gelatinolytic activity was stable at both KLK14 concentrations (Figure 4D). Lastly, there was no observable proMMP17 gelatinolytic activity, despite the expected molecular mass shift of its mature form, visible in the zymogram gel (Figure 4E). MMP17 is unlikely acting as a gelatinase, which is consistent with some previous reports of others [26].

A

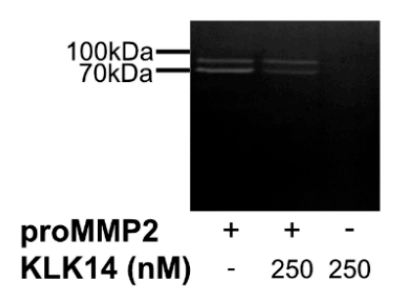

B

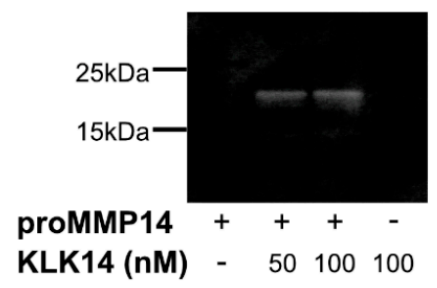

D

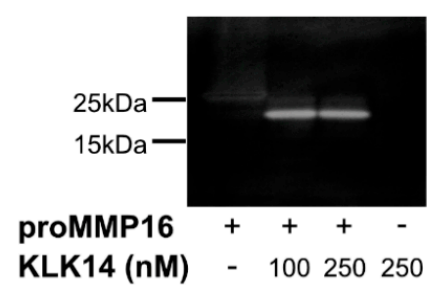

C

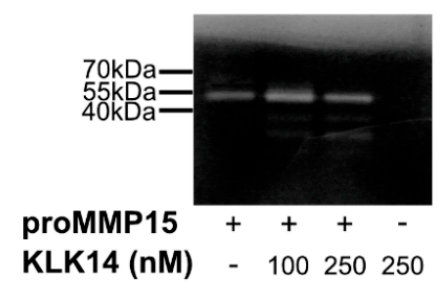

E

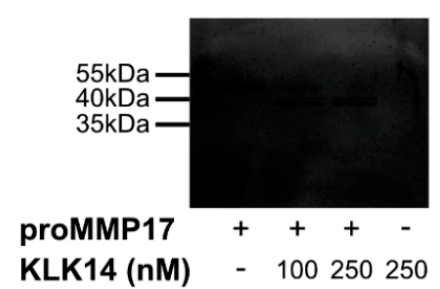

Figure 4. Gelatin zymography of proMMPs by KLK14-mediated processing. Activation of proMMPs by KLK14 results in a fully functional mature enzyme. Each proMMP was incubated with the indicated concentrations of KLK14 for $1 \mathrm{~h}$ at $37^{\circ} \mathrm{C}$. The reaction was stopped by the addition of KLK14-specific inhibitors, and the reaction mixture was analyzed by SDS-PAGE, followed by a zymogram with gelatin as a substrate. The proMMP2 (A) negative control was not activated. ProMMP14 (B), proMMP15 (C), and proMMP16 (D) were activated, whereas proMMP17 (E) did not show hydrolysis of gelatin; yet a shift corresponding to the loss of the profragment was observed (note that an amino acid substitution was introduced in proMMP17 by the manufacturer (R\&D Systems, Abingdon, United Kingdom)). KLK = kallikrein-related peptidase; MMP = matrix metalloproteinase. 


\subsection{Comparison of Functional Activation of proMMP14 by KLK14 and Furin}

Native recombinant proteins illustrated that furin and KLK14 have similar proMMP14 activation efficiency. Therefore, to confirm the equivalence of KLK14 and furin processing, increase in proMMP14 activity on a synthetic substrate was observed in parallel upon treatment with these convertases. Observed activity of KLK14/furin-treated MMP14 increased evenly for $30 \mathrm{~min}$. However, after $1 \mathrm{~h}$, the KLK14-mediated activation lead to 2-fold higher MMP14 activity when compared to furin. This difference remained consistent for the remaining $180 \mathrm{~min}$ of hydrolysis. As expected, neither KLK14 or furin had no observable activity on the MMP14 fluorescent substrate (Figure 5).

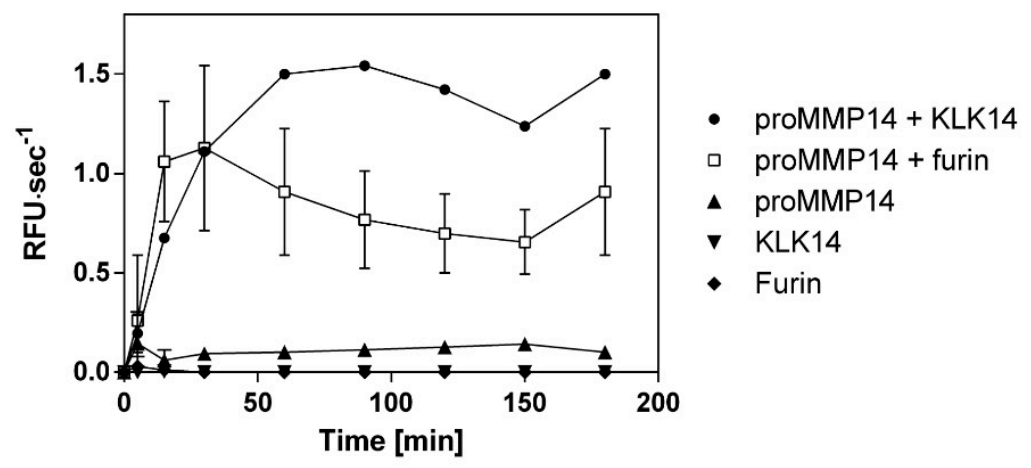

Figure 5. Comparison of recombinant human proMMP14 activation by KLK14 and furin as a functional peptidase. ProMMP14 (10 nM) was incubated with KLK14 $(3 \mathrm{nM})$ and furin $(3 \mathrm{nM})$ in the presence of a fluorogenic substrate Mca-KPLGL-Dpa-AR-NH2. The final concentration of the substrate was $10 \mu \mathrm{M}$ in the MMP reaction buffer ( $50 \mathrm{mM}$ Tris, $3 \mathrm{mM} \mathrm{CaCl} 2,1 \mu \mathrm{M} \mathrm{ZnCl} 2, \mathrm{pH}$ 8.5). Hydrolysis was recorded for $180 \mathrm{~min}$ at $37^{\circ} \mathrm{C}$. The velocities were plotted in triplicates as mean \pm SD using GraphPad Prism. Please note that the error bars may be occluded by the point markers and are not visible for some of the data points. $\mathrm{KLK}=$ kallikrein-related peptidase; $\mathrm{MMP}=$ matrix metalloproteinase.

\subsection{Cell Surface Processing of proMMP14 by KLK14}

A key step in demonstrating whether KLK14 activates proMMP14 at the cell surface is to validate whether it can occur in a cellular system. For this, murine fibroblasts stably expressed with human MMP14 (MT1-MMP) were grown to obtain a cell density of 1 million cells/well. Cells were treated with active KLK14 and furin, along with appropriate controls, and surface protein biotinylation was performed, followed by immunoprecipitation of the biotinylated proteins and a MMP14-specific Western blot. The specific bands for MMP14 were seen with a corresponding $\sim 63 \mathrm{kDa}$ and $\sim 58 \mathrm{kDa}$ molecular mass (Figure 6) and were interpreted as proMMP14 and active MMP14, respectively, in accordance with the previous records $[27,28]$. Upon cell stimulation with $50 \mathrm{nM}$ KLK14 for $30 \mathrm{~min}$, an increase in intensity of the $58 \mathrm{kDa}$ band was observed. Furthermore, a processed MMP14 form was detected at a slightly lower molecular mass of $\sim 56 \mathrm{kDa}$. This form also appeared in a KLK14 concentration-dependent manner and was stable up to $500 \mathrm{nM} \mathrm{KLK14}$ (Figure S2). Interestingly, furin did not facilitate an increase in intensity in any of the bands, nor did it produce any lower-molecular weight products, detectable on Western blot. 


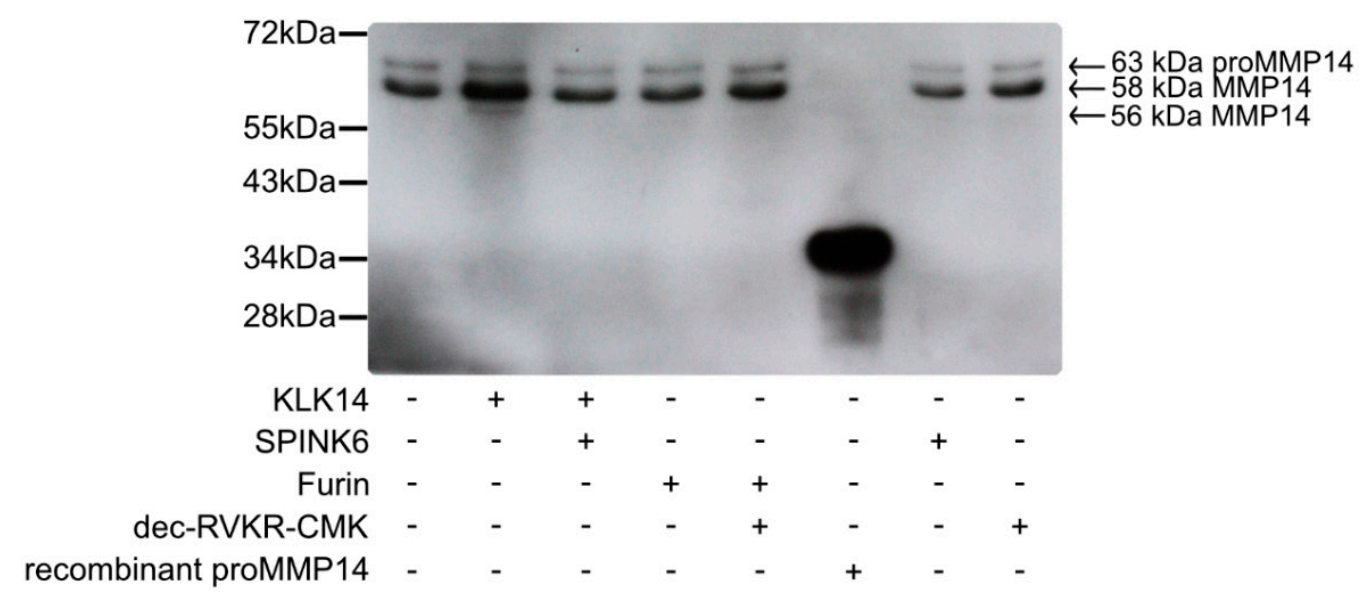

Figure 6. Processing of cell surface proMMP14 by KLK14. Murine fibroblasts stably expressing human MMP14 (MT1-MMP) were treated with KLK14 and furin. Selective inhibitors serine protease inhibitor Kazal-type 6 (SPINK6) (KLK14) and dec-RVKR-CMK (furin) were used to inhibit KLK and furin in the control samples. Cell surface proteins were then biotinylated, and streptavidin bead immunoprecipitates were subjected to immunoblotting using an anti-MMP14 antibody. Each sample contained the $63 \mathrm{kDa}$ proMMP14 form, whereas an increase in the active $58 \mathrm{kDa}$ MMP14 form was observed after KLK14 incubation. Additionally, a lower molecular weight MMP14 form at $56 \mathrm{kDa}$ was detected only in the KLK14 treated sample. KLK = kallikrein-related peptidase; MMP = matrix metalloproteinase.

\section{Discussion}

Matrix metalloproteinases are essential enzymes in the maintenance of tissue homeostasis, namely by regulation of its self-reorganization, through growth factor activation and processing, as well as involvement in the regulation of immune cell functions [29]. Herein, we present biochemical evidence of selective activation of membrane-type MMPs by the kallikrein-related protease family member KLK14.

Our assessment is based on an unbiased approach, where all proMMP-specific activation sequences were displayed utilizing a hybrid protein system, allowing for easy production, purification and fragmentation analysis. The described herein CleavEx (Cleavage of exposed amino acid sequences) system facilitated a rapid selection of KLK14-specific candidate proMMPs for further analysis with recombinant proteins. The carrier protein, HmuY, is produced by the bacterium responsible for periodontitis, Porphyromonas gingivalis, which uses an arsenal of proteolytic enzymes as virulence factors [30]. Stability studies indicate an unsurpassed resistance of the HmuY protein to proteolytic digestion by trypsin and bacterial proteinases alike [23] and suggest enhanced stability in situ (i.e., in inflamed tissue). Furthermore, structural studies revealed that the $\mathrm{N}$ - and C-termini of HmuY are exposed to the solvent and are thus easily accessible, while the overall globular structure of $\mathrm{HmuY}$ ensures good solubility and ease of folding when produced recombinantly [23]. The N-terminal HisTag serves as an affinity label for purification and additionally as a degradation-specific tag for follow-up of peptide bond hydrolysis, even in complex protein mixtures. Previously, a similar approach, but using a modified fibroblast growth factor-1 (FGF-1), was implemented by another group in the analysis of a proKLK cascade activation [31,32] and MMP-dependent activation of KLKs [33]. Yet, we believe the choice of HmuY used herein to be superior. The approximate $25 \mathrm{kDa}$ molecular masses of the CleavEx fusion proteins and the $\sim 2.5 \mathrm{kDa}$ N-terminal fragment removal allowed for an easy follow-up of the reaction products by SDS-PAGE and Western blot in comparison to the FGF-1-based system, characterized by a $\sim 1 \mathrm{kDa}$ shift only.

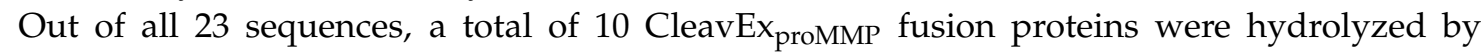
KLK14, specifically the ones corresponding to membrane-type MMPs (MMP14-17 and MMP24-25), stromelysin-3 (MMP11), MMP21, femalysin (MMP23), and epilysin (MMP28) activation sequences 


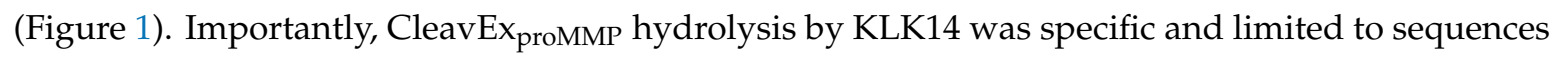
derived from a subset of metalloprotease zymogens. Strikingly, the majority of all proMMPs recognized by KLK14 in the CleavEx analysis, cluster together constituting the group of membrane-type (MT) MMPs. This subgroup of the MMP proteinases is bound to the plasma membrane, either by type I transmembrane domains (MMP14-16, MMP24) or by means of phosphatidylinositol-anchors attached to the protein chains (MMP17 and MMP25) [20]. Therefore, recognition by KLK14 reflects not only the similarities in the activation domain of MT-MMPs but also the common evolutionary ancestry and functional homology of the processed proteinases. Together, these results indicate that the group of cell-surface proMMPs can be nearly exclusively targeted by KLK14-mediated activation (Figure 7).

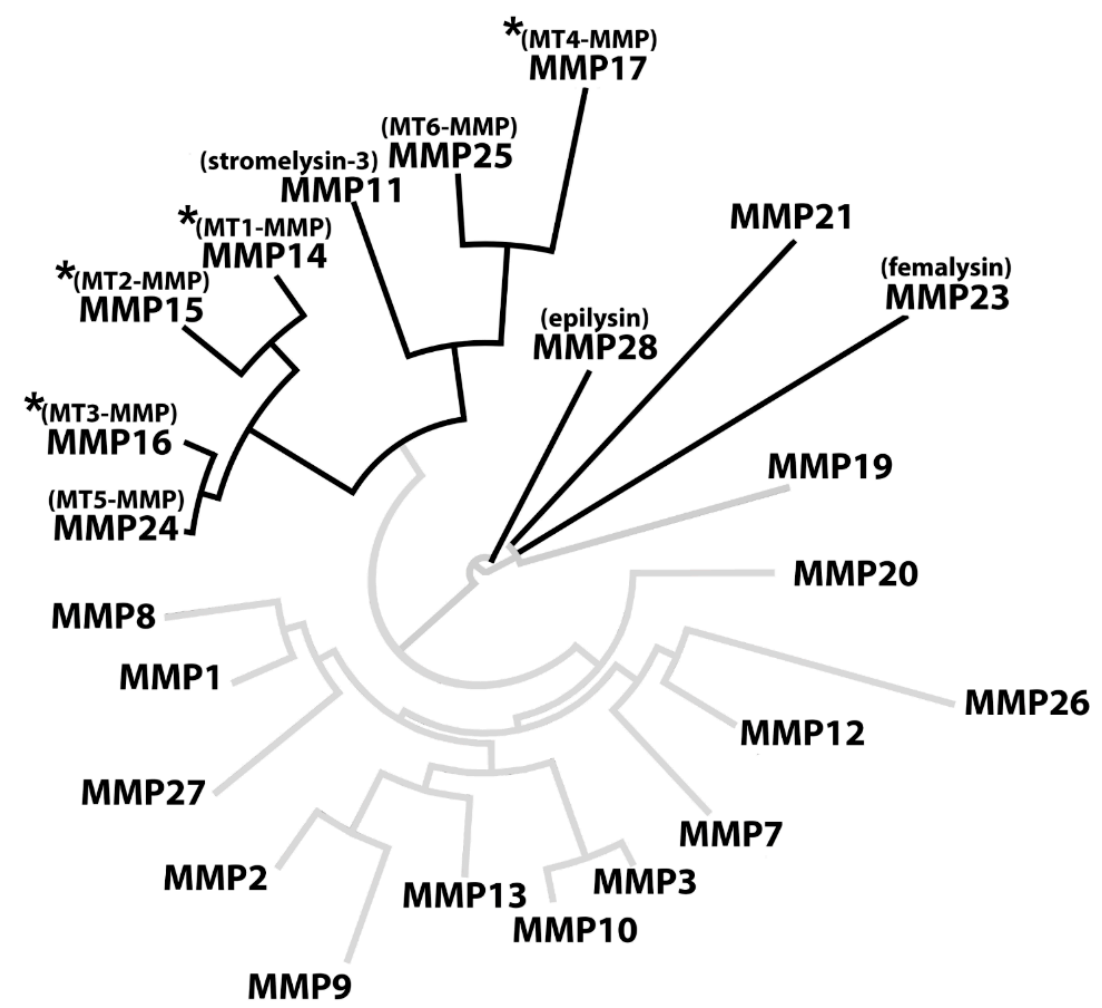

Figure 7. KLK14-activated MMPs cluster together in phylogenetic analysis. The full sequences of all human MMPs were obtained from the uniport database and analyzed in BioEdit using built-in multiple alignment ClustalW algorithm. The resulting alignment was visualized using an online tool (www.phylogeny.fr). The full black branches represent the MMPs in which the profragment activation sequence was hydrolyzed by KLK14. An asterisk denotes MMPs processed by KLK14 as verified in vitro. $\mathrm{MMP}=$ matrix metalloproteinase; $\mathrm{MT}-\mathrm{MMP}=$ membrane-type matrix metalloproteinase.

Commercially available recombinant proMMPs were investigated to confirm the initial CleavEx $x_{\text {proMMP }}$ analysis. KLK14 was an effective convertase for proMMP14 and proMMP16 but less-efficiently, for proMMP15 and proMMP17 in a time dependent manner (Figure 3). N-terminal sequencing of the concentration-dependent KLK14-released products identified the expected hydrolysis sites for proMMP14, proMMP15, and proMMP16, respectively, indicating native-like processing of these enzymes by KLK14 [13,24] (Table 2). ProMMP14 processing by KLK14 and furin revealed a single band corresponding to the active form (Figure 2C,D). No $12 \mathrm{kDa}$ prodomain was visible upon KLK14 treatment, while furin released an intact profragment observed on SDS-PAGE. This KLK14-mediated prodomain processing may be vital in the disruption of the non-covalent association between the MMP14 prodomain and catalytic domain. As observed in the activity assay using a synthetic substrate, KLK14-mediated MMP14 activation was more efficient than furin, which may be due to the prodomain still being non-covalently attached serving as inhibitor of MMP14 [34] 
(Figure 5). In addition, the identified $\mathrm{G}^{298}-\mathrm{I}^{299}$ internal cleavage of MMP15 was located in the hinge region connecting the catalytic domain and hemopexin domain [35] (Table 2). It is difficult to predict the impact of this cleavage on the protease activity of the resulting MMP15 and its specificity towards protein substrates. However, the appearance of a corresponding band in the zymogram analysis indicated ability to cleave gelatin and suggested that this specific auto-processing by initial KLK14-mediation may be responsible for shedding of the active catalytic domain of MMP15 from the cell surface (Figure 4C). Interestingly, the cell surface localization of MMP15 was essential for its ability to cleave collagen in cell-based assays, and it was required for exhibition of invasive cancer cell phenotypes [36,37], while soluble MMP15 was found to display a nearly 13-fold higher activity on triple-helical substrates compared to the cell-surface located form [38]. This suggests, that release of the mature MMP15 from the cell surface may be an important regulatory step, resulting in enhanced triple helical collagen I degradation. Furthermore, lower concentrations of KLK14 induced step-wise MMMP16 profragment processing, as revealed by two truncated proforms, one form corresponding to KLK14 specificity (KKPR ${ }^{100} \downarrow C G$ ) and the other to the specificity of MMP16 [25] (Figure 2F and Table 2). The processing of $\mathrm{KKPR}^{100} \downarrow C G$, illustrates that KLK14 recognizes the site adjacent to cysteine-sulfhydryl group within the prodomain that associates with the catalytic zinc, which may disrupt the noncovalent interaction vital in releasing an active MMP16. Lastly, two distinct bands were present in the proMMP17 untreated samples both with identical N-termini, suggesting the difference between these products is in the C-terminal region (Figure 2G). KLK14 processed both proMMP17 forms and generated two bands, both again with the same N-termini, three amino acids upstream at the motif TQAR ${ }^{122} \downarrow R R P Q$ (Table 2). However, as described in the manufacturer documentation, the proMMP17 activation site $\mathrm{R}^{125}$ was exchanged to $\mathrm{P}^{125}$ therefore the native activation site is not accessible for proteolysis, which in turn targets a secondary activation site.

The verification of the hydrolysis sites at the expected activation location (except for proMMP17) indicates the proper processing of the proMMP by KLK14; however, it does not confirm the production of the active metalloproteinase from its zymogen form. To validate that KLK14-mediated processing does in fact release mature and functional MMP proteinases, gelatin zymography was employed (Figure 4). It confirmed MMP14, 15, and 16 as functional proteinases since clear bands appeared at the expected molecular mass shifts of processed MMPs. Despite the correct mass shift, proMMP17 displayed no gelatinolytic activity, either due to the abovementioned modification of the native activation site or the natural low activity of MMP17 on gelatin as a substrate [26]. It is worth noting, however, that all commercially available proMMP14-17 preparations do not contain the membrane-interacting domain, located in the C-terminal region of the mature forms, which may impact activation kinetics in vivo. Therefore, demonstrating whether KLK14 activates MT-MMP in a cellular system provides increasing evidence of an inter-activating KLK and MT-MMP network.

Recently, a KLK4/KLK14 activity system on the cell surface of COS-7 cells was described [17]. The authors propose a cell surface-located organization of a proteinase complex, containing hepsin and transmembrane serine protease 2 (TMPRSS2), two membrane-bound serine proteinases, which recruit KLK4 and KLK14 and activate proMMP3 and proMMP9. In this complex, KLK14 undergoes specific activation and accumulates in the active form, bound to the plasma membrane by a so far unknown mechanism. The role of cell surface-bound KLK14 in that system was not identified. However, based on the data presented in our study, we believe and propose that the proximity of MT-MMPs to membrane-attached, proteolytically active KLK14 may provide a yet undescribed platform for the activation of MT-MMPs.

As exemplified by the archetypical member of the subfamily, MT1-MMP (MMP14), this subclass of MMPs was reported to undergo furin-dependent activation in the compartments of the late secretory pathway; however, a body of research challenges this earlier assumption [13]. An alternative activation pathway was identified in furin-deficient RPE.40 cells which were able to display active MMP14 with the same $\mathrm{N}$-terminus as the native form found in furin-expressing COS-7 cells [13]. As furin expressing CHO-K1 cells processed the membrane-bound form to the same extent as RPE.40 cells, while also 
converting the soluble form of MMP14, the authors concluded, that furin is required only for the maturation of the soluble form. Other, yet unidentified enzymes are responsible for the processing of membrane bound MMP14 [13]. Similarly, the non-constitutive, furin-independent processing of proMMP14 was also reported to occur in fibrosarcoma HT-1080 and CCL-137 normal fibroblast cells, where the $63 \mathrm{kDa}$ proform of MMP14 was detected in both, the tumor-derived cell line and in normal cells upon PMA stimulation $[39,40]$. Thus, a furin-independent activation pathway needs to be further elucidated since active MMP14 was still present in furin-deficient cells [41-43].

MMP14 is expressed quite low in cells normally between 100,000-200,000 sites/cell, which makes it difficult to perform biochemical analysis and investigate functional parameters [44]. To delve into its processing, the MT1-MMP (MMP14) gene is transfected either transiently or stably, which results in MMP14 overexpression, leading to a plethora of cell surface forms; $63 \mathrm{kDa}$ proenzyme, $54 \mathrm{kDa}$ enzyme; and a $39-45 \mathrm{kDa}$ degradation products [27]. The work presented here shows MMP14 to be processed on the cell surface by KLK14 using murine fibroblasts stably overexpressing MMP14 (Figure 6). The $\sim 63$ and $58 \mathrm{kDa}$ forms detected by immunoprecipitation are consistent with previous reports and were identified as proMMP14 and active MMP14, respectively $[27,28]$. Indeed, the intensity of the $58 \mathrm{kDa}$ band increased upon KLK14 treatment. In addition, a lower-molecular weight MMP14 form of around $56 \mathrm{kDa}$ appeared. Intriguingly, this may present an alternative location of processing the membrane anchored proMMP14 by KLK14, as potential locations corresponding with KLK14 specificity are present $\sim 1$ and $4 \mathrm{kDa}$ downstream in the MMP14 sequence (TPK ${ }^{134}$ and IRK $^{146}$, respectively). Furthermore, in our experiments, furin did not process cell surface proMMP14, also consistent with previous reports, indicating that furin acts exclusively in the Golgi apparatus and/or on soluble, not-membrane-bound forms of MMP14 [41].

Researchers confirmed that there is a 2-step activation process for MT1-MMP. The linkage (RRPRC ${ }^{93} \mathrm{GVPD}$ ) in the prodomain maintains the latent proenzyme by chelating the cysteine-sulfhydryl group to the active site zinc, which furin hydrolysis alone is not enough to disrupt the interaction [34]. Most importantly, mutant forms of the MMP dependent cleavage site (PGD $\downarrow \mathrm{L}^{50}$ ) and furin activation site (RRKR ${ }^{111} \downarrow Y^{112}$ ) sequences in HT 1080 cells showed both proenzyme and enzyme forms of MMP14 on their cell surface, thus again confirming a furin-independent pathway of MMP14 processing [34]. This cell-surface processing sheds more light on the potential of various secreted MMP14 forms to be differentially regulated in normal and cancer cells by extracellular KLK14. In addition to KLK14 hydrolyzing the furin recognition site (RRKR $\left.{ }^{111} \downarrow Y^{112}\right)$, KLK14 may also recognize the trypsin-like sequence, $R R P R{ }^{92} C G V P D$, which is specifically adjacent to the site of the cysteine-sulfhydryl group within the prodomain that associates with the catalytic zinc in the active site. In the work presented here (Figure 2C,D), when recombinant proMMP14 was incubated with furin, the released prodomain was intact and visible, which confirms furin hydrolysis is limited to only the furin recognition site [45]. On the other hand, KLK14 further degraded the released prodomain since it was no longer visible at $12 \mathrm{kDa}$ as compared to furin. Thus, this indicates the additional KLK14 hydrolysis in the prodomain, which may be vital in the release non-covalent association of the prodomain and catalytic domain once KLK14 or furin cleave at the furin recognition site. Intriguingly, KLK14 recognized this highly conserved cysteine linkage sequence, $\mathrm{KKPR}^{100} \downarrow C G V P D$, within the prodomain of recombinant MMP16 (Table 2). This illustrates the possibility of KLK14 to disrupt the prodomain association with the catalytic zinc in other proMMPs in vivo, providing a universal activation mechanism for the entire proMMP family by KLK14. Nonetheless, recombinant proMMP2 also contains the corresponding ${ }^{97} \mathrm{MRKPR}^{101} \mathrm{C}$ sequence; yet no KLK14-mediated activation was observed, indicating that accessibility to this sequence may be selective and depend on protein conformation (Figure 2A).

The proteolytic network interactions between the KLKs and MMPs are starting to emerge. In vitro analysis studies illustrate that MMPs can modulate KLK activity, such as MMP20 activating proKLK1, 4, and 6, as well as MMP3 activating proKLK4 [33,46]. Furthermore, major MMPs involved in tumor progression (proMMP1, 2, and 9) have been shown to be activated by KLK1, which may lead to enhanced tissue homeostasis or dysregulation [47]. Cell surface-located, membrane type MMPs have 
been identified as important players in bone remodeling, as well as in wound healing, growth factor signaling, and in immune functions [48-50], while KLKs are implicated in immune functions and TGF $\beta$ activation [51]. Interestingly, the presence of both MT-MMPs and KLKs was identified in many types of cancer [50,52]. A body of research indicates MMP14 as the main membrane type MMP essential for cancer cell escape and hence, tumor progression $[53,54]$, which is partially attributed to proMMP2 activation, but also for the ability of MMP14 to directly degrade type I collagen and to promote cellular invasion in 3D collagen matrices [55]. Similarly, MMP15 and MMP16 were shown to promote invasiveness of tumor cells in 3D fibrin matrices [10,56], while, in particular, MMP16 is highly expressed in aggressive melanoma [10]. MMP17 was implicated as a protease critical for breast cancer metastasis in animal models [57]. KLK14 was similarly implicated in many human tumors. Most notably, KLK14 levels were found to predict poor outcomes in prostate cancer patients [58], and elevated levels of both transcript and protein were found in malignant breast cancer tissues [59,60]. In correlation, increased levels of MMP14 were detected in prostate cancer cells [61,62], and active MMP2 was found to be inversely correlated with the disease-free survival time in prostate cancer patients [61]. Furthermore, elevated levels of MMP14 were associated with poor prognosis and invasiveness in breast cancer $[63,64]$. Recently, the involvement of MMP14 was also indicated in epithelial-to-mesenchymal transition in squamous cell carcinoma [65,66] and prostate cancer alike [67].

It is therefore exciting to speculate, that the herein described potential of KLK14 to activate membrane-type MMPs may provide a novel mechanism facilitating prostate and breast tumorigenesis, initial cancer cell invasion, and subsequent tumor progression at the sites of metastases formation. In addition, future studies include profiling more KLKs utilizing the CleavEx analysis to better understand the proteolytic network interaction between KLKs and proMMPs.

\section{Materials and Methods}

\subsection{Cloning of HmuY-Based CleavEx Fusion Proteins}

The CleavEx fusion proteins were constructed based on a proteolysis-resistant Porphyromonas gingivalis HmuY protein (accession number ABL74281.1) as a carrier via PCR cloning. Firstly, the HmuY gene was amplified using primers forward: $5^{\prime}$-atatgcggccgcagacgagccgaaccaaccctcca- $3^{\prime}$ and reverse: $5^{\prime}$-atactcgagttatttaacggggtatgtataagcgaaagtga- $3^{\prime}$ from whole-genomic DNA isolated from $P$. gingivalis strain W83. PCR was conducted for 35 cycles with initial denaturation at $98^{\circ} \mathrm{C}$, followed by $40 \mathrm{~s}$ annealing at $68{ }^{\circ} \mathrm{C}$ and $30 \mathrm{~s}$ extension at $72{ }^{\circ} \mathrm{C}$, using Phusion DNA polymerase (Thermo Fisher Scientific, Waltham, MA, USA) and T100 Thermal Cycler (Bio-Rad, Hercules, CA, USA). The HmuY PCR product was further amplified in three consecutive PCR reactions with primers specific to the $5^{\prime}$ HmuY fragment and a $3^{\prime}$ specific primer introducing additional nucleotides dependent on the designed sequence (Table 3) at the same conditions. All sequences were designed based of the accession number from the Uniprot database (www.uniprot.org): MMP1 (P03956), MMP2 (P08253), MMP3 (P08254), MMP7 (P09237), MMP8 (P22894), MMP9 (P14780), MMP10 (P09238), MMP11 (P24347), MMP12 (P39900), MMP13 (P45452), MMP14 (P50281), MMP15 (P51511), MMP16 (P51512), MMP17 (Q9ULZ9), MMP19 (Q99542), MMP20 (O60882), MMP21 (Q8N119), MMP23 (O75900), MMP24 (Q9Y5R2), MMP25 (Q9NPA2), MMP26 (Q9NRE1), MMP27 (Q9H306), and MMP28 (Q9H239). Lastly, the final PCR reaction was ligated into a modified pETDuet plasmid, according to the manufacturers protocol, with potential tryptic cleavage sites removed from the MCS using QuickChange (Agilent Technologies, Santa Clara, CA, USA). An alternative method was also used for the fusion protein-encoding sequences by using Phusion Site-Directed Mutagenesis (Thermo Fisher Scientific, Waltham, MA, USA) via sequence exchange from a previously prepared CleavEx construct (Table 4). The final product was transformed into competent E. coli $\mathrm{T} 10$ cells and then purified and sequenced. All CleavEx $x_{\text {proMMP }}$ DNA sequences were identified to be as intended. 
Table 3. Primers used for generating the proMMP CleavEx fusion proteins using three consecutive PCRs.

\begin{tabular}{|c|c|c|}
\hline Protein Name & Primer & Primer Sequence $\left(5^{\prime}-3^{\prime}\right)$ \\
\hline & reverse * & ATATGCGGCCGCTTATTTAACGGGGTATGTATAAGCGA \\
\hline proMMP15 & forward 1 & GCCCTCACCGGGAGGGACGAGCCGAACCAACCCT \\
\hline proMMP15 & forward 2 & CGGAAGCGCTACGCCCTCACCGGGAGGGAC \\
\hline proMMP15 & forward 3 & ATATGTCGACCGGCGTCGGAAGCGCTACGCCCTCA \\
\hline proMMP17 & forward 1 & GCTCCAGCCCCCACCGACGAGCCGAACCAACCCT \\
\hline proMMP17 & forward 2 & AGGAGACGCCAGGCTCCAGCCCCCACCGAC \\
\hline proMMP17 & forward 3 & ATATGTCGACGCTCGCAGGAGACGCCAGGCTCCAG \\
\hline proMMP19 & forward 1 & CTGTTGCTGGGCCGCGACGAGCCGAACCAACCCT \\
\hline proMMP19 & forward 2 & ACССТTAAATACСTGTTGCTGGGCCGCGAC \\
\hline proMMP19 & forward 3 & ATATGTCGACCAGAAGACCCTTAAATACCTGTTGCTGG \\
\hline proMMP21 & forward 1 & CCGCGGGCGCCGCTGGACGAGCCGAACCAACCCT \\
\hline proMMP21 & forward 2 & TCCAGGCGCTCCCCGCGGGCGCCGCTGGAC \\
\hline proMMP21 & forward 3 & ATATGTCGACGCCCGCTCCAGGCGCTCCCCGCGG \\
\hline proMMP24 & forward 1 & GCCCTGACTGGACAGGACGAGCCGAACCAACCCT \\
\hline proMMP24 & forward 2 & GAAACAAGCGCTATGCCCTGACTGGACAGGAC \\
\hline proMMP24 & forward 3 & ATATGTCGACCGGAGAAACAAGCGCTATGCCCT \\
\hline proMMP25 & forward 1 & CTGAGCGGCAGCGACGAGCCGAACCAACCCT \\
\hline proMMP25 & forward 2 & CGCCGGTACGCTCTGAGCGGCAGCGAC \\
\hline proMMP25 & forward 3 & ATATGTCGACAGGCGGCGTCGCCGGTACGCTCTGAGC \\
\hline proMMP28 & forward 1 & GCAAAGCAAGGTAACGACGAGCCGAACCAACCCT \\
\hline proMMP28 & forward 2 & TAAGAAACGCTTTGCAAAGCAAGGTAACGACGAG \\
\hline proMMP28 & forward 3 & ATATGTCGACAGGCGTAAGAAACGCTTTGCAAAGCAAG \\
\hline
\end{tabular}

Table 4. Primers used for generating the proMMP CleavEx fusion proteins using mutagenesis.

\begin{tabular}{ccc}
\hline Protein Name & Primer & Primer Sequence $\mathbf{( 5 P}^{\prime} \mathbf{- 3}^{\prime} \mathbf{)}$ \\
\hline & $\begin{array}{c}\text { reverse } \\
\text { forward }\end{array}$ & GTCGACCTGCAGGCTCGC \\
proMMP1 & GAUGUGGCGCAGUUUGUGCUGACCGACGAGCCGAACCAACCC \\
proMMP2 & forward & GAUGUGGCGAACUAUAACUUUUUUGACGAGCCGAACCAACCC \\
proMMP3 & forward & GAUGUGGGUCAUUUUCGUACCUUUGACGAGCCGAACCAACCC \\
proMMP7 & forward & GAUGUGGCGGAAUAUAGCCUGUUUGACGAGCCGAACCAACCC \\
proMMP8 & forward & GGUGGUUUUAUGCUGACCCCGGGUGACGAGCCGAACCAACCC \\
proMMP9 & forward & GAUCUGGGU CGUUUUCAGACCUUUGACGAGCCGAACCAACCC \\
proMMP10 & forward & GAUGUGGGUCAUUUUAGCAGCUUUGACGAGCCGAACCAACCC \\
proMMP11 & forward & CGUCAGAAACGUUUUGUGCUGAGCGACGAGCCGAACCAACCC \\
proMMP12 & forward & GAAAUGCCGGGUGGUCCGGUGUGGGACGAGCCGAACCAACCC \\
proMMP13 & forward & GAUGUGGGUGAAUAUAACGUGUUUGACGAGCCGAACCAACCC \\
proMMP14 & forward & CGUCGUAAACGUUAUGCGAUUCAGGACGAGCCGAACCAACCC \\
proMMP16 & forward & CGUCGUAAACGUUAUGCGCUGACCGACGAGCCGAACCAACCC \\
proMMP20 & forward & GAUGUGGCGAACUAUCGUCUGUUUGACGAGCCGAACCAACCC \\
proMMP23 & forward & CGUCGUCGUCGUUAUACCCUGCCGGACGAGCCGAACCAACCC \\
proMMP26 & forward & GAUGGUAGCGAUACCAGCAUUAGCGACGAGCCGAACCAACCC \\
proMMP27 & forward & GAUGUGGGUCAGUAUGGUUAUACCGACGAGCCGAACCAACCC \\
\hline
\end{tabular}

\subsection{Expression and Purification of CleavEx Fusion Proteins}

The designed fusion proteins covering proMMP activation sequences were expressed using an E. coli BL21 expression system. Following the $0.5 \mathrm{mM}$ IPTG induction at $\mathrm{OD}_{600 \mathrm{~nm}}=0.5-0.6$, the bacterial culture protein production was facilitated for $3 \mathrm{~h}$ at $37^{\circ} \mathrm{C}$, with shaking. Then, the bacteria were spun down, and the pellet was suspended in buffer A (10 mM sodium phosphate, $500 \mathrm{mM} \mathrm{NaCl}$, and $5 \mathrm{mM}$ imidazole, $\mathrm{pH} 7.4$ ) and sonicated ( $15 \mathrm{~min}$ at $16^{\circ} \mathrm{C}$, pulse $6 \mathrm{~s}$, amplitude $\left.70 \%\right)$. Supernatant of the soluble proteins was then loaded onto the HisTrap ${ }^{\mathrm{TM}}$ Excel (GE Healthcare, Chicago, IL, USA) column in buffer A and eluted with a linear gradient of $0-100 \%$ of $1 \mathrm{M}$ imidazole in buffer A in 20 column volumes $(\mathrm{CV})$. Protein containing fractions were pooled together and exchanged into $50 \mathrm{mM}$ Tris $\mathrm{pH} 7.5$ and 
then purified by ion exchange chromatography using a MonoQ 4.6/100 PE column (GE Healthcare, Chicago, IL, USA) with a linear gradient of $0-100 \% 50 \mathrm{mM}$ Tris $\mathrm{pH} 7.5,1 \mathrm{M} \mathrm{NaCl}$ in $15 \mathrm{CV}$. Purity of all the products was verified by SDS-PAGE.

\subsection{Expression and Production of KLK14}

The gene encoding human proKLK14 was custom-synthesized by Life Technologies (Carlsbad, CA, USA) with a codon usage optimized for Leishmania tarentolae and cloned into the pLEXSY_I-blecherry3 plasmid (Cat. No. EGE-243, JenaBioscience, Jena, Germany) using NotI and XbaI restriction sites. All preparations for transfection, selection, and expression in host strain T7-TR of L. tarentolae were performed according to the JenaBioscience protocol for inducible expression of recombinant proteins secreted to the medium. Expression of proKLK14 was induced with $15 \mu \mathrm{g} / \mathrm{mL}$ of tetracycline (BioShop, Burlington, Canada) and was carried out for 3 days. Next, the media was spun down (20 min at $3000 \mathrm{rcf}$ ), and the supernatant was precipitated with $80 \%$ ammonium sulfate for $1 \mathrm{~h}$ at $4{ }^{\circ} \mathrm{C}$ and then centrifuged ( $30 \mathrm{~min}$ at 15,000 $\mathrm{rcf}$ ). The pellet was suspended in $10 \mathrm{mM}$ sodium phosphate, $500 \mathrm{mM} \mathrm{NaCl}$, and $5 \mathrm{mM}$ imidazole, $\mathrm{pH} 7.4$ in the presence of $5 \mathrm{mM}$ benzamidine and dialyzed overnight at $4^{\circ} \mathrm{C}$ in the same buffer. The following day, the solution was loaded onto HisTrap ${ }^{\mathrm{TM}}$ Excel (GE Healthcare) as described above (Section 4.2). Obtained fractions were analyzed by SDS PAGE and fractions containing proKLK14 were concentrated with Vivaspin@2 (Sartorius, Göttingen, Germany) and further purified on Superdex s75 pg (GE Healthcare, Chicago, IL, USA) in 20 mM Tris pH 7.5, $0.5 \mathrm{M} \mathrm{NaCl}$. After purification and self-activation overnight at $4{ }^{\circ} \mathrm{C}$, KLK14 was active-site titrated as described in Kantyka et al. [68].

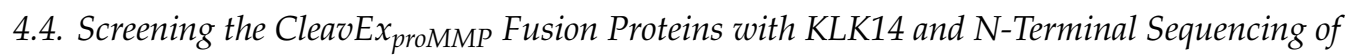 KLK14-Released Fragments}

CleavEx proteins were incubated at a 1:1000 and 1:200 KLK14:CleavExproMMP molar ratio, corresponding to 50 and $250 \mathrm{nM}$ KLK14, respectively, in $50 \mathrm{mM}$ Tris pH 7.5. In addition, lower KLK14 concentrations (10, 25, and $50 \mathrm{nM})$ were tested on CleavEx proMMP11, 14-17, 24, 25 , and 28. Samples were incubated at $37^{\circ} \mathrm{C}$ for $1 \mathrm{~h}$, after which the reactions were immediately stopped by the addition of $50 \mathrm{mM}$ DTT-supplemented SDS sample buffer (1:1) and boiled. The obtained samples were resolved using 10\% Tricine SDS-PAGE. The proteins were electrotransferred onto a PVDF membrane (Amersham $^{\mathrm{TM}}$ Hybond $^{\mathrm{TM}}$, GE Healthcare) in $25 \mathrm{mM}$ Tris, $190 \mathrm{mM}$ glycine, and 20\% methanol at $100 \mathrm{~V}$ for $1 \mathrm{~h}$ in $4{ }^{\circ} \mathrm{C}$. The membranes were blocked with 5\% skim milk in TTBS (50 mM Tris- $\mathrm{HCl}, 500 \mathrm{mM}$ $\mathrm{NaCl}, 0.05 \%$ Tween-20, pH 7.5) and incubated with an anti-HisTag-HRP antibody (catalog no. A7058, Sigma-Aldrich, St. Louis, MO, USA) diluted 1:20 000 in TTBS. The Western blots were developed with Pierce®ECL Western blotting substrate (Thermo Fisher Scientific, Waltham, MA, USA) using Medical X-Ray-Film Blue (Agfa HealthCare, Mortsel, Belgium).

Furthermore, each hydrolyzed CleavEx promMP $(1 \mu \mathrm{g})$ was incubated with $250 \mathrm{nM}$ KLK14 for $1 \mathrm{~h}$ at $37^{\circ} \mathrm{C}$, the reactions were stopped, and the products were resolved on SDS-PAGE and electrotransferred onto a PVDF membrane [69]. The membranes were stained with Coomassie Brilliant Blue R-250 (BioShop, Burlington, Canada) and the bands of interest were sequenced via automated Edman degradation using a PPSQ/31B protein sequencer (Shimadzu Biotech, Kyoto, Japan) equipped with an LC-20AT HPLC, CTO-20A column heater and SPD20A UV detector (Shimadzu Biotech) for on-line PTH analysis. Data was recorded using proprietary software (Shimadzu Biotech), and the sequence was determined by visual inspection of the UV $269 \mathrm{~nm}$ chromatograms.

\subsection{SDS-PAGE Analysis of KLK14-Mediated Recombinant proMMP Processing}

A total of $0.5 \mu \mathrm{g}$ native proMMP2 (catalog no. 902-MP-010, R\&D Systems, Abingdon, United Kingdom), $0.5 \mu \mathrm{g}$ proMMP14 (catalog no. 918-MP-010, R\&D Systems), $1 \mu$ g proMMP15 (catalog no. 916-MP-010, R\&D Systems), 0.5 mg proMMP16 (catalog no. 1785-MP-010, R\&D Systems), and $1 \mu \mathrm{g}$ proMMP17 (catalog no. 7796-MP-010, R\&D Systems) were separately incubated in $10 \mu \mathrm{L}$ with a 
range of KLK14 concentrations (25-250 nM, with molar ratios from around 1:65 to 1:10 KLK14:MMP) in the presence of $5 \mu \mathrm{M}$ batimastat (Sigma-Aldrich, St. Louis, MO, USA) for $1 \mathrm{~h}$ at $37^{\circ} \mathrm{C}$ in PBS. As a positive control, a total of $1 \mu \mathrm{g}$ native proMMP2 and $0.5 \mu \mathrm{g}$ proMMP14 were separately incubated in $10 \mu \mathrm{L}$ with a range of furin (catalog no. 1503-SE-010, R\&D Systems) concentrations (0-250 nM, molar ratios from around 1:65 to 1:6). The reactions were stopped with the addition of $50 \mathrm{mM}$ DTT-supplemented SDS sample buffer $(1: 1, v: v)$ and boiled. The samples were resolved using SDS-PAGE as described above and then visualized with Coomassie Brilliant Blue G-250 (Bioshop, Burlington, Canada) staining. Additionally, 50 nM KLK14 (proMMP14) or 100 nM KLK14 (proMMP15, proMMP16, and proMMP17) was incubated with each respective proMMP $(0.5 \mu \mathrm{g}$ proMMP14 and 16, $1 \mu \mathrm{g}$ proMMP15 and 17) in the presence of $5 \mu \mathrm{M}$ batimastat for specified periods of time (0-180 min). The final molar ratio for KLK14:MMP14 was 1:32, KLK14:MMP15 was 1:16, KLK14:MMP16 was 1:16, and KLK14:MMP17 was 1:18. The reaction in each sample was stopped as above and SDS-PAGE separation was visualized using Coomassie Brilliant Blue G-250.

\subsection{N-Terminal Sequencing of KLK14 Processed Recombinant proMMPs}

Each native proMMP $(2 \mu \mathrm{g})$ was incubated with $50 \mathrm{nM}$ (proMMP14) or $250 \mathrm{nM}$ (proMMP15, proMMP16, proMMP17) KLK14 for $1 \mathrm{~h}$ at $37^{\circ} \mathrm{C}$ and resolved by SDS-PAGE as described above. Proteins were then electrotransferred onto a PVDF membrane in $10 \mathrm{mM}$ CAPS, 10\% methanol, pH 11 using the Trans-blot semi-dry transfer cell (Bio-Rad, Hercules, CA, USA) at 15V for $30 \mathrm{~min}$. The membrane was stained with Coomassie Brilliant Blue R-250 (BioShop, Burlington, Canada), and bands of interest were sequenced via Edman degradation as described above.

\subsection{Zymogram Analysis of Recombinant proMMP by KLK14}

Each native proMMP $(0.5 \mu \mathrm{g})$ was incubated with 50 and 100 nM KLK14 (proMMP14) or 100 and $250 \mathrm{nM}$ KLK14 (proMMP15, 16, and 17) for $1 \mathrm{~h}$ at $37^{\circ} \mathrm{C}$. After incubation, KLK14 was inhibited with $10 \mu \mathrm{M}$ biotin-Tyr-Gly-Pro-Arg-CMK, a specific KLK14 inhibitor, and $1 \mu \mathrm{M}$ serine protease inhibitor Kazal-type 6 (SPINK6) [70] for $15 \mathrm{~min}$ at $37^{\circ} \mathrm{C}$. Next, non-reducing sample buffer (1:1) was added, and samples were incubated for $30 \mathrm{~min}$ at $37^{\circ} \mathrm{C}$. Then, samples were separated using a Tricine-SDS gel containing $0.1 \%$ gelatin at $4{ }^{\circ} \mathrm{C}$ and $40 \mathrm{~mA}$. Subsequently, the gels were washed three times with $2.5 \%$ Triton $\mathrm{X}-100$, followed by overnight incubation in assay buffer with the presence of the KLK14 inhibitors at $37^{\circ} \mathrm{C}$. The assay buffer used for each proMMP was $50 \mathrm{mM}$ Tris, $10 \mathrm{mM} \mathrm{CaCl}, 150 \mathrm{mM}$ $\mathrm{NaCl}$, pH 7.5 (proMMP2), 50 mM Tris, 3 mM CaCl $, 1 \mu \mathrm{M} \mathrm{ZnCl}_{2}, \mathrm{pH} 8.5$ (proMMP14 and 16), $50 \mathrm{mM}$ Tris, $500 \mathrm{mM} \mathrm{NaCl}, 5 \mathrm{mM} \mathrm{CaCl}, 1 \mu \mathrm{M} \mathrm{ZnCl}_{2}, \mathrm{pH} 8$ (proMMP15) and $50 \mathrm{mM}$ Tris, $10 \mathrm{mM} \mathrm{CaCl}$, pH 7.5 (proMMP17). The next day, the zymogram was fixed by using 30\% methanol with 10\% acetic acid for 2 min and stained with $0.1 \%$ amido black in $10 \%$ acetic acid for $2 \mathrm{~h}$ at room temperature, followed by destaining with $10 \%$ acetic acid.

\subsection{Functional Activation of Recombinant proMMP14 Using A Synthetic Substrate}

ProMMP14 (10 nM) was separately incubated with KLK14 (3 nM) and furin (3nM) in the presence of the fluorogenic substrate Mca-KPLGL-Dpa-AR-NH 2 (catalog no. ES010, R\&D Systems, Abingdon, United Kingdom). The final substrate concentration was $10 \mu \mathrm{M}$ in $50 \mathrm{mM}$ Tris, $3 \mathrm{mM} \mathrm{CaCl2,1} \mu \mathrm{M}$ $\mathrm{ZnCl2}$, pH 8.5. Hydrolysis was recorded for $180 \mathrm{~min}$ at $37^{\circ} \mathrm{C}\left(\lambda_{\mathrm{ex}} 320 \mathrm{~nm} ; \lambda \mathrm{e}_{\mathrm{m}} 405 \mathrm{~nm}\right) \mathrm{using}$ a microplate fluorescence reader (Molecular Devices Spectra Max GEMINI EM, Molecular Devices, San Jose, CA, USA). The measurement was performed in triplicate, and the initial velocities were determined via the built-in linear regression algorithm. The velocities were plotted in triplicates as mean \pm SD using GraphPad Prism (GraphPad Software, La Jolla, CA, USA) using time points 0, 5, 15, $30,60,90,120,150$, and $180 \mathrm{~min}$. 


\subsection{Cell Surface Processing of proMMP14 (MT1-MMP) by KLK14}

Timp 2-/- mouse embryonic fibroblast (MEF) cells stably expressing FLAG-tagged MT1-MMP transfected with the pGW1GH/hMT1-MMP expression vector [71] were seeded in a 12-well plate (250,000 cells per well) and cultured in $1.5 \mathrm{~mL}$ selection medium DMEM (Gibco, Waltham, MA, USA) with 10\% FBS (Gibco), $25 \mu \mathrm{g} / \mathrm{mL}$ mycophenolic acid (Sigma-Aldrich, St. Louis, MO, USA), $250 \mu \mathrm{g} / \mathrm{mL}$ xanthine (Sigma-Aldrich), and 1X HT supplement (Life Technologies, Carlsbad, CA, USA) for 2 days at $37^{\circ} \mathrm{C}, 5 \% \mathrm{CO}_{2}$ to $80 \%$ confluency. The selection media was aspirated, and cells were gently washed with PBS and then treated with $250 \mu \mathrm{L}$ DMEM containing either $50 \mathrm{nM}$ KLK14, $50 \mathrm{nM}$ furin and each enzyme preincubated $\left(15 \mathrm{~min}\right.$ at $\left.37^{\circ} \mathrm{C}\right)$ with its specific inhibitor: either $250 \mathrm{nM}$ SPINK6 [70] or $1 \mu \mathrm{M}$ decanoyl-RVKR-CMK (Bachem, Bubendorf, Switzerland), respectively, and further incubated for $30 \mathrm{~min}$ at $37^{\circ} \mathrm{C}, 5 \% \mathrm{CO}_{2}$. In addition, separate cell populations were incubated with increasing concentrations of $\operatorname{KLK} 14$ (50, 100, 250, and $500 \mathrm{nM}$ ) and compared to the appropriate control samples, which included: (i) untreated cells; (ii) cells treated with SPINK6 and (iii) dec-RVKR-CMK inhibitors; (iv) $50 \mathrm{nM}$ furin; (v) $50 \mathrm{nM}$ furin with $1 \mu \mathrm{M}$ dec-RVKR-CMK; and (vi) $500 \mathrm{nM}$ KLK14 in the presence of $1 \mu \mathrm{M}$ SPINK6.

The supernatant was aspirated and the cells were rinsed with cold PBS three times and then treated with $0.1 \mathrm{mg} / \mathrm{mL}$ EZ-link ${ }^{\mathrm{TM}}$ Sulfo-NHS-LC-Biotin (Thermo Fisher Scientific, Waltham, MA, USA) for $1 \mathrm{~h}$. Next, the cells were washed three times with PBS containing $100 \mathrm{mM}$ glycine and then lysed with $500 \mu \mathrm{L}$ RIPA buffer (10 mM Tris pH 7.5, $150 \mathrm{mM} \mathrm{NaCl}, 1 \%$ NP-40, 0.1\% SDS, 1\% DOC, 2 mM EDTA) containing 25X cOmplete ${ }^{\mathrm{TM}}$ EDTA-free Protease Inhibitor Cocktail (Roche, Mannheim, Germany) and $5 \mathrm{mM}$ EDTA. Cells were detached and spun down 16,000 $\mathrm{rcf}$ for $15 \mathrm{~min}$ at $4{ }^{\circ} \mathrm{C}$. The protein concentration of the lysate was determined using the Pierce ${ }^{\mathrm{TM}}$ BCA Protein Assay Kit (Thermo Fisher Scientific, Waltham, MA, USA) according to the manufacturer's instructions. A total of $500 \mu \mathrm{g}$ was loaded onto PureProteome streptavidin magnetic beads (Merck Millipore, Burlington, MA, USA) and incubated overnight at $4{ }^{\circ} \mathrm{C}$. The beads were washed twice in RIPA buffer followed by a twice wash in PBS and then suspended in $50 \mathrm{mM}$ Tris $\mathrm{pH} 7.5$ and $6 \times$ reducing sample buffer to a final $3 \times$ reducing sample buffer $(v / v)$ in a final $40 \mu \mathrm{L}$ volume. Samples were boiled at $95{ }^{\circ} \mathrm{C}$ for $5 \mathrm{~min}$, resolved on SDS-PAGE, and electrotransferred onto a PVDF membrane [69].

The membrane was subsequently blocked with $5 \%$ skim milk in TTBS $(50 \mathrm{mM}$ Tris- $\mathrm{HCl}, 500 \mathrm{mM}$ $\mathrm{NaCl}, 0.05 \%$ Tween-20, pH 7.5) for $2 \mathrm{~h}$ at $37^{\circ} \mathrm{C}$. Next, primary antibody rabbit-anti-MMP14 (catalog no. MA5-32076, Thermo Fisher Scientific, Waltham, MA, USA) in 5\% milk was added at 1:1000 overnight at $4{ }^{\circ} \mathrm{C}$. The following day, the membrane was washed four times with TTBS, and secondary antibody goat-anti rabbit-HRP (catalog no. A7058, Sigma-Aldrich, St. Louis, MO, USA) was added at 1:60,000 in $5 \%$ milk for $2 \mathrm{~h}$ at RT. Lastly, the membrane was rinsed four times with TTBS and developed with the

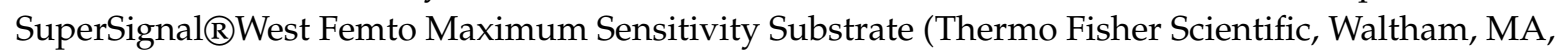
USA) using Medical X-Ray-Film Blue (Agfa HealthCare, Mortsel, Belgium).

Supplementary Materials: The following are available online at http://www.mdpi.com/1422-0067/21/12/4383/s1,

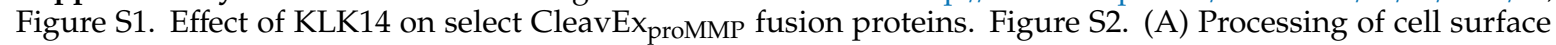
proMMP14 by KLK14. (B) Densitometry analysis of the $56 \mathrm{kDa}$ band using ImageJ, the data is represented as a log of arbitrary density units

Author Contributions: Conceptualization, K.F., K.P., J.P. and T.K.; methodology, K.F., E.B., I.B.T., O.B., K.P., G.D., A.L., A.K., J.J.E., T.K.; validation, I.B.T., O.B., A.K. and J.J.E.; formal analysis, K.F., I.B.T., O.B. and T.K.; investigation, K.F., E.B., I.B.T., O.B., K.P., M.K., L.S., M.M., A.P. (Aleksandra Pęcak), M.W. (Magdalena Wiśniewska), N.G., M.W. (Magdalena Wysocka), A.W., M.B.-B., K.S., A.P. (Anastasija Pejkovska) and M.R.; resources, G.B. and C.M.O.; writing-original draft preparation, K.F. and T.K.; writing-review and editing, K.F., E.B., K.B., G.D., A.K., J.P. and T.K.; visualization, K.F. and T.K.; supervision, K.B., G.D., A.L., A.K., J.J.E., J.P. and T.K.; project administration, K.F., K.B., J.P. and T.K.; funding acquisition, K.F., K.B., J.P. and T.K. All authors have read and agreed to the published version of the manuscript.

Funding: This research was funded by the National Science Centre (Poland) (UMO-2013/08/W/NZ1/00696 to J.P., UMO-2016/23/N/NZ1/01517 to K.F., UMO-2016/22/E/NZ5/00332 to T.K., and grant ID 211744, Ref. 2013/08/W/NZ1/00696 to K.B.). 
Conflicts of Interest: The authors declare no conflict of interest. The funders had no role in the design of the study; in the collection, analyses, or interpretation of data; in the writing of the manuscript, or in the decision to publish the results.

\section{Abbreviations}

$\begin{array}{ll}\text { ADAM } & \text { A disintegrin and metalloproteinase } \\ \text { CleavEx } & \text { Cleavage of exposed amino acid sequences } \\ \text { ECM } & \text { Extracellular matrix } \\ \text { HmuY } & \text { Heme-binding protein } \\ \text { KLK } & \text { Kallikrein-related peptidase } \\ \text { MMP } & \text { Matrix metalloproteinase } \\ \text { MT-MMP } & \text { Membrane-type matrix metalloproteinase } \\ \text { MT1-MMP } & \text { Membrane-type 1 matrix metalloproteinase, MMP14 } \\ \text { TMPRSS2 } & \text { Transmembrane serine protease 2 }\end{array}$

\section{References}

1. Frantz, C.; Stewart, K.M.; Weaver, V.M. The extracellular matrix at a glance. J. Cell Sci. 2010, 123, 4195-4200. [CrossRef] [PubMed]

2. Hansen, N.U.B.; Genovese, F.; Leeming, D.; Karsdal, M. The importance of extracellular matrix for cell function and in vivo likeness. Exp. Mol. Pathol. 2015, 98, 286-294. [CrossRef] [PubMed]

3. Edwards, D.R.; Handsley, M.M.; Pennington, C.J. The ADAM metalloproteinases. Mol. Asp. Med. 2008, 29, 258-289. [CrossRef] [PubMed]

4. Sotiropoulou, G.; Pampalakis, G. Kallikrein-related peptidases: Bridges between immune functions and extracellular matrix degradation. Boil. Chem. 2010, 391, 321-331. [CrossRef] [PubMed]

5. Jabłońska-Trypuć, A.; Matejczyk, M.; Rosochacki, S. Matrix metalloproteinases (MMPs), the main extracellular matrix (ECM) enzymes in collagen degradation, as a target for anticancer drugs. J. Enzym. Inhib. Med. Chem. 2016, 31, 177-183. [CrossRef] [PubMed]

6. Löffek, S.; Schilling, O.; Franzke, C.W. Series 'matrix metalloproteinases in lung health and disease' edited by J. Müller-Quernheim and O. Eickelberg number 1 in this series: Biological role of matrix metalloproteinases: A critical balance. Eur. Respir. J. 2011, 38, 191-208. [CrossRef]

7. Seiki, M. The cell surface: The stage for matrix metalloproteinase regulation of migration. Curr. Opin. Cell Boil. 2002, 14, 624-632. [CrossRef]

8. Kajita, M.; Itoh, Y.; Chiba, T.; Mori, H.; Okada, A.; Kinoh, H.; Seiki, M. Membrane-Type 1 Matrix Metalloproteinase Cleaves Cd44 and Promotes Cell Migration. J. Cell Boil. 2001, 153, 893-904. [CrossRef]

9. Roncucci, L.; Sena, P.; Mariani, F.; Marzona, L.; Benincasa, M.; De Leon, M.P.; Palumbo, C. Matrix metalloproteinases 15 and 19 are stromal regulators of colorectal cancer development from the early stages. Int. J. Oncol. 2012, 41, 260-266.

10. Tatti, O.; Gucciardo, E.; Pekkonen, P.; Holopainen, T.; Louhimo, R.; Repo, P.; Maliniemi, P.; Lohi, J.; Rantanen, V.; Hautaniemi, S.; et al. MMP16 Mediates a Proteolytic Switch to Promote Cell-Cell Adhesion, Collagen Alignment, and Lymphatic Invasion in Melanoma. Cancer Res. 2015, 75, 2083-2094. [CrossRef]

11. Gonzalo, P.; Moreno, V.; Gálvez, B.G.; Arroyo, A.G. MT1-MMP and integrins: Hand-to-hand in cell communication. BioFactors 2010, 36, 248-254. [CrossRef] [PubMed]

12. Nagase, H. Cell surface activation of progelatinase A (proMMP-2) and cell migration. Cell Res. 1998, 8, 179-186. [CrossRef] [PubMed]

13. Yana, I.; Weiss, S.J. Regulation of Membrane Type-1 Matrix Metalloproteinase Activation by Proprotein Convertases. Mol. Boil. Cell 2000, 11, 2387-2401. [CrossRef] [PubMed]

14. Vilen, S.-T.; Suojanen, J.; Salas, F.; Risteli, J.; Ylipalosaari, M.; Itkonen, O.; Koistinen, H.; Baumann, M.; Stenman, U.-H.; Sorsa, T.; et al. Trypsin-2 Enhances Carcinoma Invasion by Processing Tight Junctions and Activating ProMT1-MMP. Cancer Investig. 2012, 30, 583-592. [CrossRef]

15. Ra, H.-J.; Parks, W.C. Control of matrix metalloproteinase catalytic activity. Matrix Boil. 2007, 26, 587-596. [CrossRef] 
16. Carmeliet, P.; Moons, L.; Lijnen, R.; Baes, M.; Lemaître, V.; Tipping, P.; Drew, A.; Eeckhout, Y.; Shapiro, S.; Lupu, F.; et al. Urokinase-generated plasmin activates matrix metalloproteinases during aneurysm formation. Nat. Genet. 1997, 17, 439-444. [CrossRef]

17. Reid, J.C.; Matsika, A.; Davies, C.M.; He, Y.; Broomfield, A.; Bennett, N.C.; Magdolen, V.; Srinivasan, B.; Clements, J.A.; Hooper, J. Pericellular regulation of prostate cancer expressed kallikrein-related peptidases and matrix metalloproteinases by cell surface serine proteases. Am. J. Cancer Res. 2017, 7, 2257-2274.

18. Kalińska, M.; Meyer-Hoffert, U.; Kantyka, T.; Potempa, J. Kallikreins - The melting pot of activity and function. Biochim. 2015, 122, 270-282. [CrossRef]

19. Shaw, J.L.; Diamandis, E. Distribution of 15 Human Kallikreins in Tissues and Biological Fluids. Clin. Chem. 2007, 53, 1423-1432. [CrossRef]

20. Page-McCaw, A.; Ewald, A.J.; Werb, Z. Matrix metalloproteinases and the regulation of tissue remodelling. Nat. Rev. Mol. Cell Boil. 2007, 8, 221-233. [CrossRef]

21. Duarte, S.; Baber, J.; Fujii, T.; Coito, A.J. Matrix metalloproteinases in liver injury, repair and fibrosis. Matrix Boil. 2015, 44, 147-156. [CrossRef] [PubMed]

22. Tan, R.J.; Liu, Y. Matrix metalloproteinases in kidney homeostasis and diseases. Am. J. Physiol. Physiol. 2012, 302, F1351-F1361. [CrossRef] [PubMed]

23. Wójtowicz, H.; Guevara, T.; Tallant, C.; Olczak, M.; Sroka, A.; Potempa, J.; Solà, M.; Olczak, T.; Gomis-Rüth, F.X. Unique Structure and Stability of HmuY, a Novel Heme-Binding Protein of Porphyromonas gingivalis. PLoS Pathog. 2009, 5, e1000419. [CrossRef]

24. Kang, T.; Nagase, H.; Pei, D. Activation of membrane-type matrix metalloproteinase 3 zymogen by the proprotein convertase furin in the trans-Golgi network. Cancer Res. 2002, 62, 675-681. [PubMed]

25. Kukreja, M.; Shiryaev, S.A.; Cieplak, P.; Muranaka, N.; Routenberg, D.A.; Chernov, A.V.; Kumar, S.; Remacle, A.G.; Smith, J.W.; Kozlov, I.A.; et al. High-Throughput Multiplexed Peptide-Centric Profiling Illustrates Both Substrate Cleavage Redundancy and Specificity in the MMP Family. Chem. Boil. 2015, 22, 1122-1133. [CrossRef] [PubMed]

26. Kolkenbrock, H.; Essers, L.; Ulbrich, N.; Will, H. Biochemical Characterization of the Catalytic Domain of Membrane-Type 4 Matrix Metalloproteinase. Boil. Chem. 1999, 380, 1103-1108. [CrossRef] [PubMed]

27. Golubkov, V.S.; Chernov, A.V.; Strongin, A.Y. Intradomain Cleavage of Inhibitory Prodomain Is Essential to Protumorigenic Function of Membrane Type-1 Matrix Metalloproteinase (MT1-MMP) in Vivo*. J. Boil. Chem. 2011, 286, 34215-34223. [CrossRef]

28. Chellaiah, M.A.; Ma, T. Membrane Localization of Membrane Type 1 Matrix Metalloproteinase by CD44 Regulates the Activation of Pro-Matrix Metalloproteinase 9 in Osteoclasts. BioMed Res. Int. 2013, 2013, 302392. [CrossRef]

29. Sternlicht, M.D.; Werb, Z. How Matrix Metalloproteinases Regulate Cell Behavior. Annu. Rev. Cell Dev. Boil. 2001, 17, 463-516. [CrossRef]

30. Guo, Y.; Nguyen, K.-A.; Potempa, J. Dichotomy of gingipains action as virulence factors: From cleaving substrates with the precision of a surgeon's knife to a meat chopper-like brutal degradation of proteins. Periodontology 2010, 54, 15-44. [CrossRef]

31. Yoon, H.; Laxmikanthan, G.; Lee, J.; Blaber, S.I.; Rodríguez, A.; Kogot, J.M.; Scarisbrick, I.A.; Blaber, M. Activation Profiles and Regulatory Cascades of the Human Kallikrein-related Peptidases. J. Boil. Chem. 2007, 282, 31852-31864. [CrossRef] [PubMed]

32. Yoon, H.; Blaber, S.I.; Evans, D.M.; Trim, J.; Juliano, M.A.; Scarisbrick, I.A.; Blaber, M. Activation profiles of human kallikrein-related peptidases by proteases of the thrombostasis axis. Protein Sci. 2008, 17, 1998-2007. [CrossRef] [PubMed]

33. Yoon, H.; Blaber, S.I.; Li, W.; Scarisbrick, I.A.; Blaber, M. Activation profiles of human kallikrein-related peptidases by matrix metalloproteinases. Boil. Chem. 2013, 394, 137-147. [CrossRef] [PubMed]

34. Golubkov, V.S.; Cieplak, P.; Chekanov, A.V.; Ratnikov, B.I.; Aleshin, A.E.; Golubkova, N.V.; Postnova, T.I.; Radichev, I.A.; Rozanov, D.V.; Zhu, W.; et al. Internal Cleavages of the Autoinhibitory Prodomain Are Required for Membrane Type 1 Matrix Metalloproteinase Activation, although Furin Cleavage Alone Generates Inactive Proteinase*. J. Boil. Chem. 2010, 285, 27726-27736. [CrossRef] 
35. Osenkowski, P.; Meroueh, S.O.; Pavel, D.; Mobashery, S.; Fridman, R. Mutational and Structural Analyses of the Hinge Region of Membrane Type 1-Matrix Metalloproteinase and Enzyme Processing. J. Boil. Chem. 2005, 280, 26160-26168. [CrossRef]

36. Hotary, K.; Allen, E.; Punturieri, A.; Yana, I.; Weiss, S.J. Regulation of Cell Invasion and Morphogenesis in a Three-Dimensional Type I Collagen Matrix by Membrane-Type Matrix Metalloproteinases 1, 2, and 3. J. Cell Boil. 2000, 149, 1309-1323. [CrossRef]

37. Ota, I.; Li, X.-Y.; Hu, Y.; Weiss, S.J. Induction of a MT1-MMP and MT2-MMP-dependent basement membrane transmigration program in cancer cells by Snail1. Proc. Natl. Acad. Sci. USA 2009, 106, 20318-20323. [CrossRef]

38. Pahwa, S.; Bhowmick, M.; Amar, S.; Cao, J.; Strongin, A.Y.; Fridman, R.; Weiss, S.J.; Fields, G.B. Characterization and regulation of MT1-MMP cell surface-associated activity. Chem. Boil. Drug Des. 2018, 93, 1251-1264. [CrossRef]

39. Osenkowski, P.; Toth, M.; Fridman, R. Processing, shedding, and endocytosis of membrane type 1-matrix metalloproteinase (MT1-MMP). J. Cell. Physiol. 2004, 200, 2-10. [CrossRef]

40. Lohi, J.; Lehti, K.; Westermarck, J.; Kähäri, V.-M.; Keski-Oja, J. Regulation of Membrane-Type Matrix Metalloproteinase-1 Expression by Growth Factors and Phorbol 12-Myristate 13-Acetate. JBIC J. Boil. Inorg. Chem. 1996, 239, 239-247. [CrossRef]

41. Cao, J.; Rehemtulla, A.; Bahou, W.; Zucker, S. Membrane Type Matrix Metalloproteinase 1 Activates Pro-gelatinase A without Furin Cleavage of the N-terminal Domain. J. Boil. Chem. 1996, 271, 30174-30180. [CrossRef] [PubMed]

42. Sato, T.; Kondo, T.; Seiki, M.; Ito, A. Cell type-specific involvement of furin in membrane type 1 matrix metalloproteinase-mediated progelatinase A activation. Ann. N. Y. Acad. Sci. 1999, 878, 713-715. [CrossRef] [PubMed]

43. Sato, T.; Kondo, T.; Fujisawa, T.; Seiki, M.; Ito, A. Furin-independent Pathway of Membrane Type 1-Matrix Metalloproteinase Activation in Rabbit Dermal Fibroblasts. J. Boil. Chem. 1999, 274, 37280-37284. [CrossRef] [PubMed]

44. Remacle, A.G.; Chekanov, A.V.; Golubkov, V.S.; Savinov, A.Y.; Rozanov, D.; Strongin, A.Y. O-Glycosylation Regulates Autolysis of Cellular Membrane Type-1 Matrix Metalloproteinase (MT1-MMP). J. Boil. Chem. 2006, 281, 16897-16905. [CrossRef]

45. Golubkov, V.S.; Chekanov, A.V.; Shiryaev, S.A.; Aleshin, A.E.; Ratnikov, B.I.; Gawlik, K.; Radichev, I.; Motamedchaboki, K.; Smith, J.W.; Strongin, A.Y. Proteolysis of the membrane type-1 matrix metalloproteinase prodomain: Implications for a two-step proteolytic processing and activation. J. Biol. Chem. 2007, 282, 36283-36291. [CrossRef]

46. Beaufort, N.; Plaza, K.; Utzschneider, D.T.; Schwarz, A.; Burkhart, J.M.; Creutzburg, S.; Debela, M.; Schmitt, M.; Ries, C.; Magdolen, V. Interdependence of kallikrein-related peptidases in proteolytic networks. Boil. Chem. 2010, 391, 581-587. [CrossRef]

47. Filippou, P.S.; Karagiannis, G.S.; Musrap, N.; Diamandis, E. Kallikrein-related peptidases (KLKs) and the hallmarks of cancer. Crit. Rev. Clin. Lab. Sci. 2016, 53, 277-291. [CrossRef]

48. Tokuhara, C.K.; Santesso, M.R.; De Oliveira, G.S.N.; Ventura, T.M.O.; Doyama, J.T.; Zambuzzi, W.; Oliveira, R.C. Updating the role of matrix metalloproteinases in mineralized tissue and related diseases. J. Appl. Oral Sci. 2019, 27, e20180596. [CrossRef]

49. Caley, M.; Martins, V.L.; O’Toole, E. Metalloproteinases and Wound Healing. Adv. Wound Care 2015, 4, 225-234. [CrossRef]

50. Turunen, S.P.; Tatti-Bugaeva, O.; Lehti, K. Membrane-type matrix metalloproteases as diverse effectors of cancer progression. Biochim. Biophys. Acta (BBA) Bioenerg. 2017, 1864, 1974-1988. [CrossRef]

51. Sotiropoulou, G.; Pampalakis, G.; Diamandis, E. Functional Roles of Human Kallikrein-related Peptidases. J. Boil. Chem. 2009, 284, 32989-32994. [CrossRef] [PubMed]

52. Borgoño, C.A.; Diamandis, E. The emerging roles of human tissue kallikreins in cancer. Nat. Rev. Cancer 2004, 4, 876-890. [CrossRef] [PubMed] 
53. Yan, T.; Lin, Z.; Jiang, J.; Lu, S.; Chen, M.; Que, H.; He, X.; Que, G.; Mao, J.; Xiao, J.; et al. MMP14 regulates cell migration and invasion through epithelial-mesenchymal transition in nasopharyngeal carcinoma. Am. J. Transl. Res. 2015, 7, 950-958. [PubMed]

54. Von Nandelstadh, P.; Gucciardo, E.; Lohi, J.; Li, R.; Sugiyama, N.; Carpen, O.; Lehti, K. Actin-associated protein palladin promotes tumor cell invasion by linking extracellular matrix degradation to cell cytoskeleton. Mol. Boil. Cell 2014, 25, 2556-2570. [CrossRef]

55. Lowy, A.M.; Clements, W.M.; Bishop, J.; Kong, L.; Bonney, T.; Sisco, K.; Aronow, B.; Fenoglio-Preiser, C.; Groden, J.L. $\beta$-Catenin/Wnt Signaling Regulates Expression of the Membrane Type 3 Matrix Metalloproteinase in Gastric Cancer. Cancer Res. 2006, 66, 4734-4741. [CrossRef]

56. Hotary, K.B.; Yana, I.; Sabeh, F.; Li, X.-Y.; Holmbeck, K.; Birkedal-Hansen, H.; Allen, E.D.; Hiraoka, N.; Weiss, S.J. Matrix Metalloproteinases (MMPs) Regulate Fibrin-invasive Activity via MT1-MMP-dependent and -independent Processes. J. Exp. Med. 2002, 195, 295-308. [CrossRef]

57. Chabottaux, V.; Sounni, N.E.; Pennington, C.J.; English, W.R.; Brûle, F.V.D.; Blacher, S.; Gilles, C.; Munaut, C.; Maquoi, E.; Lopez-Otin, C.; et al. Membrane-Type 4 Matrix Metalloproteinase Promotes Breast Cancer Growth and Metastases. Cancer Res. 2006, 66, 5165-5172. [CrossRef]

58. Yousef, G.M.; Stephan, C.; Scorilas, A.; Ellatif, M.A.; Jung, K.; Kristiansen, G.; Jung, M.; Polymeris, M.-E.; Diamandis, E. Differential expression of the human kallikrein gene 14 (KLK14) in normal and cancerous prostatic tissues. Prostate 2003, 56, 287-292. [CrossRef]

59. Fritzsche, F.; Gansukh, T.; Borgoño, C.A.; Burkhardt, M.; Pahl, S.; Mayordomo, E.; Winzer, K.-J.; Weichert, W.; Denkert, C.; Jung, K.; et al. Expression of human Kallikrein 14 (KLK14) in breast cancer is associated with higher tumour grades and positive nodal status. Br. J. Cancer 2006, 94, 540-547. [CrossRef]

60. Papachristopoulou, G.; Avgeris, M.; Charlaftis, A.; Scorilas, A. Quantitative expression analysis and study of the novel human kallikrein-related peptidase 14 gene (KLK14) in malignant and benign breast tissues. Thromb. Haemost. 2010, 105, 131-137. [CrossRef]

61. Trudel, D.; Fradet, Y.; Meyer, F.; Harel, F.; Têtu, B. Membrane-type-1 matrix metalloproteinase, matrix metalloproteinase 2, and tissue inhibitor of matrix proteinase 2 in prostate cancer: Identification of patients with poor prognosis by immunohistochemistry. Hum. Pathol. 2008, 39, 731-739. [CrossRef] [PubMed]

62. Wang, Y.; Zhang, Y.; Kong, C.Z.; Zhang, Z.; Zhu, Y.Y. Loss of P53 facilitates invasion and metastasis of prostate cancer cells. Mol. Cell. Biochem. 2013, 384, 121-127. [CrossRef]

63. Li, Y.; Cai, G.; Yuan, S.; Jun, Y.; Li, N.; Wang, L.; Chen, F.; Ling, R.; Yun, J. The overexpression membrane type 1 matrix metalloproteinase is associated with the progression and prognosis in breast cancer. Am. J. Transl. Res. 2015, 7, 120-127. [PubMed]

64. Yao, G.; He, P.; Chen, L.; Hu, X.; Gu, F.; Ye, C. MT1-MMP in breast cancer: Induction of VEGF-C correlates with metastasis and poor prognosis. Cancer Cell Int. 2013, 13, 98. [CrossRef] [PubMed]

65. Pang, L.; Li, Q.; Li, S.; He, J.; Cao, W.; Lan, J.; Sun, B.; Zou, H.; Wang, C.; Liu, R.; et al. Membrane type 1-matrix metalloproteinase induces epithelial-to-mesenchymal transition in esophageal squamous cell carcinoma: Observations from clinical and in vitro analyses. Sci. Rep. 2016, 6, 22179. [CrossRef] [PubMed]

66. Yang, C.-C.; Zhu, L.-F.; Xu, X.-H.; Ning, T.-Y.; Ye, J.-H.; Liu, L.-K. Membrane Type 1 Matrix Metalloproteinase induces an epithelial to mesenchymal transition and cancer stem cell-like properties in SCC9 cells. BMC Cancer 2013, 13, 171. [CrossRef]

67. Cao, J.; Chiarelli, C.; Richman, O.; Zarrabi, K.; Kozarekar, P.; Zucker, S. Membrane Type 1 Matrix Metalloproteinase Induces Epithelial-to-Mesenchymal Transition in Prostate Cancer. J. Boil. Chem. 2008, 283, 6232-6240. [CrossRef]

68. Kantyka, T.; Fischer, J.; Wu, Z.; Declercq, W.; Reiss, K.; Schröder, J.-M.; Meyer-Hoffert, U. Inhibition of kallikrein-related peptidases by the serine protease inhibitor of Kazal-type 6. Peptides 2011, 32, 1187-1192. [CrossRef]

69. Matsudaira, P. Sequence from picomole quantities of proteins electroblotted onto polyvinylidene difluoride membranes. J. Boil. Chem. 1987, 262, 10035-10038. 
70. Plaza, K.; Kalinska, M.; Bochenska, O.; Meyer-Hoffert, U.; Wu, Z.; Fischer, J.; Falkowski, K.; Sasiadek, L.; Bielecka, E.; Potempa, B.; et al. Gingipains of Porphyromonas gingivalis Affect the Stability and Function of Serine Protease Inhibitor of Kazal-type 6 (SPINK6), a Tissue Inhibitor of Human Kallikreins*. J. Boil. Chem. 2016, 291, 18753-18764. [CrossRef]

71. Morrison, C.J.; Butler, G.S.; Bigg, H.F.; Roberts, C.R.; Soloway, P.D.; Overall, C.M. Cellular Activation of MMP-2 (Gelatinase A) by MT2-MMP Occurs via a TIMP-2-independent Pathway. J. Biol. Chem. 2001, 276, 47402-47410. [CrossRef] [PubMed]

(C) 2020 by the authors. Licensee MDPI, Basel, Switzerland. This article is an open access article distributed under the terms and conditions of the Creative Commons Attribution (CC BY) license (http://creativecommons.org/licenses/by/4.0/). 